\title{
Fostering the Sustainable Development Goals in Horizon Europe
}

This report is produced for the Austrian Federal Ministry of Education, Science and Research.

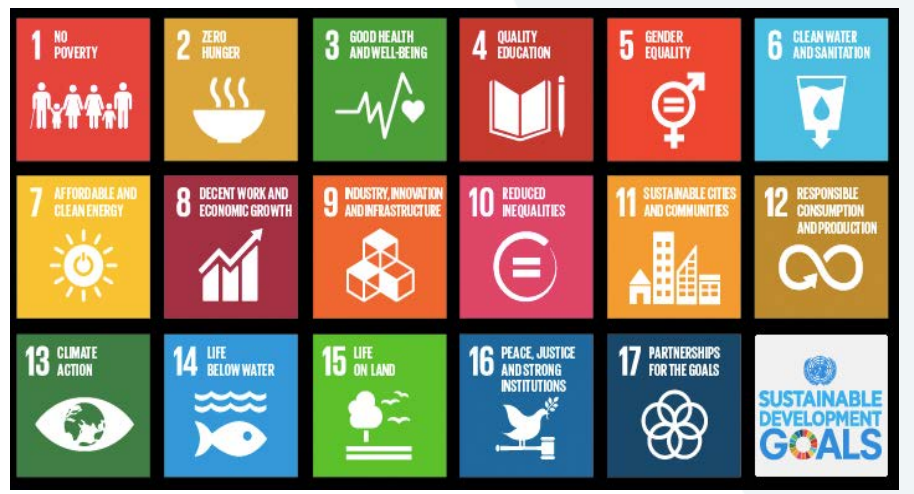

Final Report 14 Feb 2019

By Katja Mayer and Klaus Schuch, Centre for Social Innovation Vienna 


\section{Impressum}

Media proprietor and publisher

Federal Ministry of Education, Science and Research

Minoritenplatz 5, 1010 Vienna

www.bmbwf.gv.at

Authors: Katja Mayer and Klaus Schuch

Centre for Social Innovation, Vienna www.zsi.at

DOI 10.22163/fteval.2019.416

Suggested citation:

Mayer, K. and Schuch, K. (2019): Fostering the Sustainable Development Goals in Horizon

2020. Report for the Austrian Federal Ministry of Education, Science and Research. Vienna, February 2019. DOI 10.22163/fteval.2019.416

Copyright and Liability:

Excerpts may only be reproduced with reference to the source, all other rights are not permitted without the written consent of the media owner.

It is pointed out that all information in this publication, despite careful processing, is without guarantee and liability of the Federal Ministry of Education, Science and Research and the author. Legal interpretations represent the non-binding opinion of the author and cannot under any circumstances prejudge the jurisdiction of the independent courts.

Considerations on this publication can be directed to: karolina.beguschpfefferkorn@bmbwf.gv.at

All rights reserved.

Vienna 2019 


\section{Table of Contents}

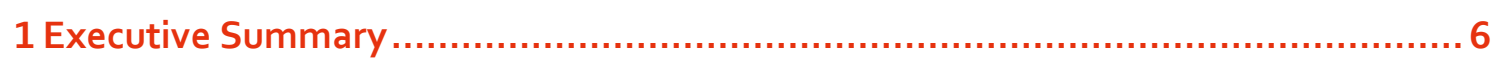

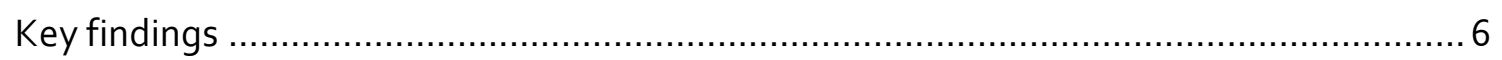

2 Introduction: SDGs in FP7, Horizon2020 and lessons learned ............................. 9

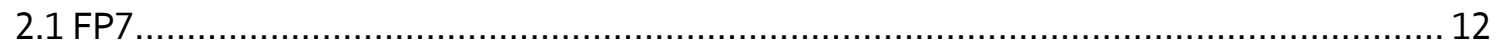

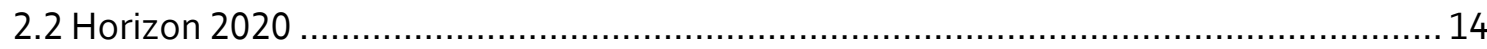

2.3 "New horizons. Future scenarios for research \& innovation policies in Europe"

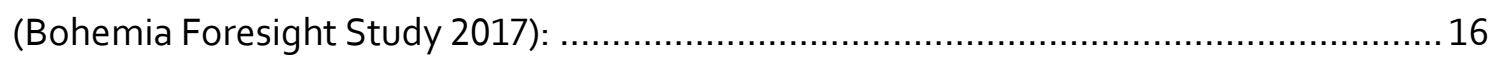

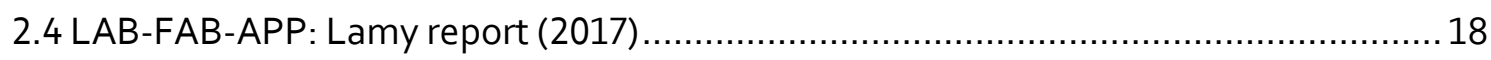

2.5 ESIR memorandum on mission-oriented research and innovation in the EU (2017)....20

2.6 RISE policy brief on "Mission-oriented research and innovation policy" (2018).......... 21

2.7 Mission-oriented research \& innovation in the European Union (Mazzucato Paper

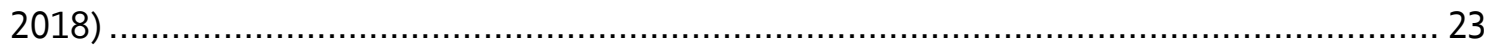

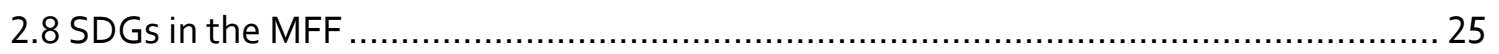

3 European policy stakeholder position statements and comments ...................... 28

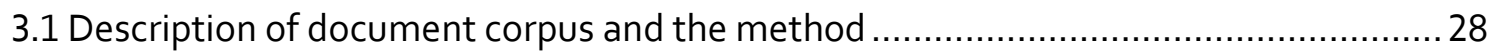

3.2 The envisioned roles of the SDGs in the next framework programme: stakeholder

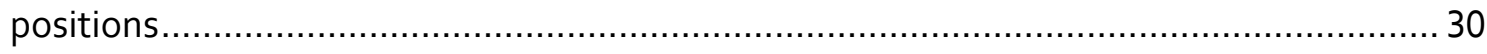

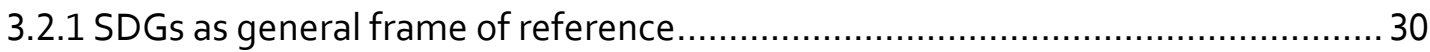

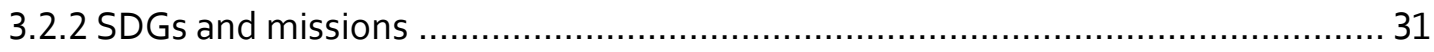

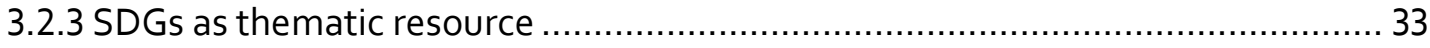

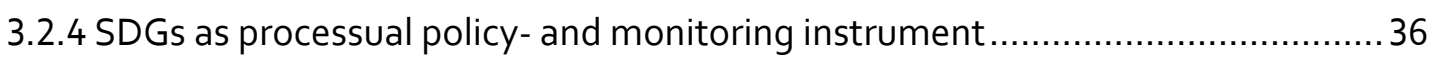

3.2.5 Mainstreaming SDGs in existing strategies and activities ............................... 37

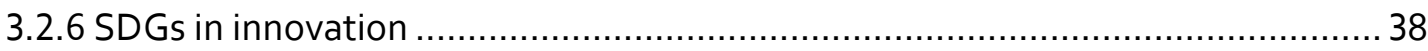

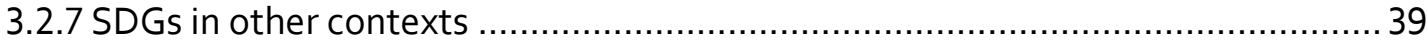

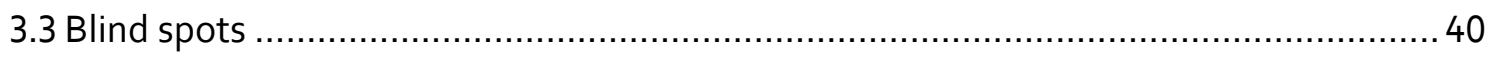



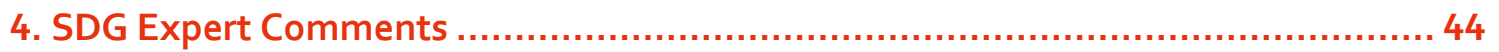


4.1 SDGs as framing and guiding vision of Horizon Europe ..................................... 44

4.2 Role and function of universities and HEls for sustainable development in R\&I ..........46

4.3 Monitoring and evaluation of STI in regard to the SDGs ........................................ 48

4.4 Instruments, incentives and best practices for the implementation of SDGs into FP9 51

4.5 (Problems of) Knowledge transfer and capacity building ........................................ 54

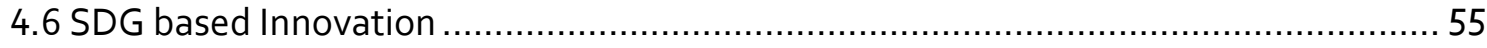

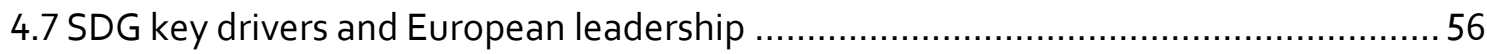

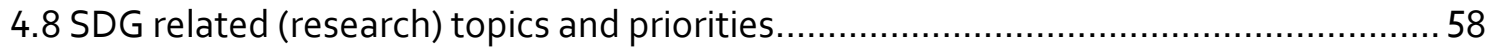

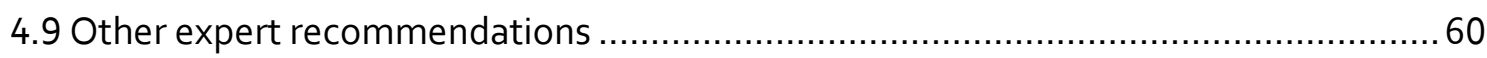

5 Reactions to the proposal for Horizon Europe .......................................... 64

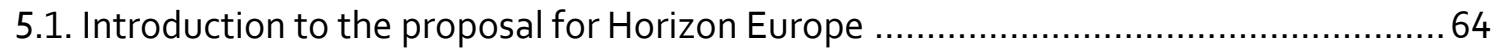

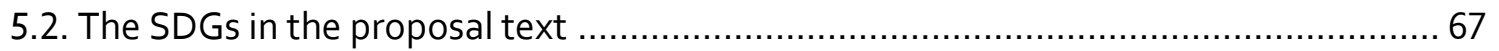

5.3. Reactions to the proposal for Horizon Europe in respect to the roles and functions of

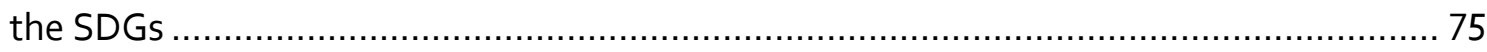

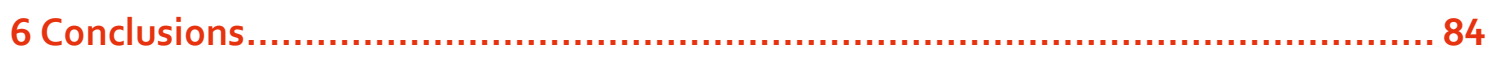

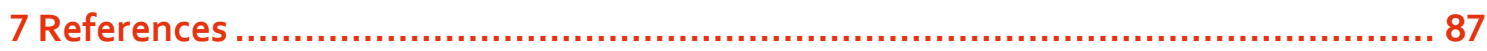

Annex 1: List of position statements issued before the publication of Horizon Europe

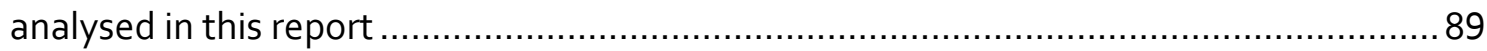

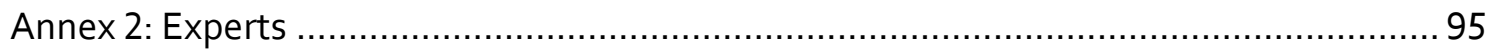

Annex 3 Expert interview guideline and questions................................................. 99

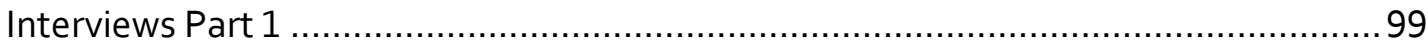

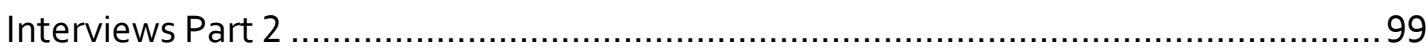

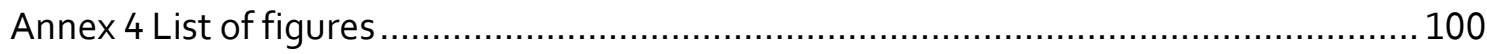




\section{Executive Summary}

This report is based on the opinion that sustainable development (SD) in general and the Sustainable Development Goals (SDG) in particular are important for the future of Europe's STI system. The main objective of the report is to describe and analyse how SD and the SDGs are appearing in European research and innovation policy related discourse, in stakeholder positions towards the next framework programme Horizon Europe (FP9), and reflect findings with experts.

\section{Resulting from a study commissioned by the Austrian Federal Ministry of Education, Science and Research in 2018 to inform the strategic planning process of Horizon Europe,} this report summarises the findings and expert recommendations in regard to the implementation of the SDGs in coming STI strategies. The report provides an overview and reflection of the representation of the SDGs in the preparation of the Horizon Europe proposal. Moreover, based on expert interviews the report outlines where and how the SDGs could be better and more effectively integrated. It is directed to a broad audience interested in the genesis of Horizon Europe and the robust implementation of the SDGs therein as well as in related strategies and policies. Hence the report serves as knowledge resource for the further development and design of frameworks for science, technology and innovation.

The analysis refers to four different sources of information:

1) Policy papers, EU communications and high-level expert group reports

2) Positions statements of stakeholders in aviso of the EC proposal for FP9

3) Narrative interviews with 8 Austrian and German SDG experts before the publication of the proposal for Horizon Europe

4) Narrative interviews with 3 experts and review of selected international reactions to the proposal for Horizon Europe

\section{Key findings}

The analysis of 86 country and stakeholder positions in aviso of Horizon Europe clearly points to SDGs being an important topic in STI visions. The analysis shows that SD and SDGs are integrated in most positions, even though to a very different degree and not always explicitly denominated. Many of the positions are also backed by expert papers and expert interviews. Interpreting the results leads to the following conclusions: 
- Sustainability is referred to in most of the documents, and the SDGs in particular are regarded as a broad multilateral social contract that was also co-shaped by innovators and industry, so there is broad acceptance. Countries are also signatories of the UN SDG Agenda and many take part in the high level political forum on SD.

- The SDGs provide a good background to negotiate not only grand visions, but also concrete priorities. They can be used both in a broad and detailed approach, depending how to be implemented. In particular, they are highly suited to bring together local and global knowledge, different types of expertise and to align actions.

- The SDGs come with a set of measurable indicators, even though indicators are still under development and need to be better adapted to European realities; they would be highly suited for monitoring impact. Therefore, robust SDG relevant monitoring has to be implemented from the beginning and designed across all STI activities

- The SDGs are a social contract. The SDGs thus would provide useful cross-links among EU programmes, such as Horizon Europe and the European Structural and Investment Funds. They could be used for thematic priorities as well as for monitoring activities and support several European strategies, most importantly support social cohesion activities.

- The SDGs need a broad mixture of knowledge and expertise. Inter- and transdisciplinarity are essential, and collaboration across the broadest spectrum of disciplines is the necessary prerequisite. Importantly, the SDGs themselves also need to become object of research, and need to be better integrated in educational priorities, in strategies for public engagement and citizen participation. Those sectors need to be further elaborated in terms of agenda setting and evaluation.

- The SDGs could serve as blueprint to analyse countries' potential STI needs and thus benefit the efforts of widening participation in EU activities. However, this would need better alignment of the European Research Area ERA, higher education policies and the SDGs.

- The majority of stakeholder positions calls for a broad understanding of innovation; therefore, the SDGs should become better institutionalised in STI decision bodies.

- Principles of excellence in research and innovation should include the SDGs

Some pressing issues and open questions to be addressed for short term and middle term priorities:

- It should be investigated how turning SDG compliance into an asset might benefit transformation and commercialisation for EU research and innovation actors and in general, future and emerging breakthrough innovations.

- How can bringing together industry leaders actively promoting the SDGs (e.g. from global innovation leading and deep-tech companies in the life science sector) and 
advocacy from civil society and policy making help to build coherent and adaptable funding streams and instruments to both benefit and enrich the mission-oriented approach and finding the right paths to advanced research. 


\section{Introduction: SDGs in FP7, Horizon2020 and lessons learned}

Resulting from a study commissioned by the Austrian Federal Ministry of Education, Science and Research in 2018 to inform the strategic planning process of Horizon Europe, this report summarises the findings and expert recommendations in regard to the implementation of the SDGs in coming STI strategies. The report provides an overview and reflection of the representation of the SDGs in the preparation of the Horizon Europe proposal. Moreover, based on expert interviews the report outlines where and how the SDGs could be better and more effectively integrated. It is directed to a broad audience interested in the genesis of Horizon Europe and the robust implementation of the SDGs therein as well as in related strategies and policies. Hence, the report serves as knowledge resource for the further development and design of frameworks for science, technology and innovation.

In 2015, the United Nations General Assembly formally adopted the 2030 Agenda for Sustainable Development, along with a set of 17 SDGs and 169 associated targets. This marks a turning point in European commitment to sustainable development. Even though sustainable development (SD) is one of the objectives in Article 3 Treaty on European Union and an official strategy since 2001, operationalised even as set of SD relevant indicators since 2005, it was not particularly prominent at the EU high level politics, probably due to lack of ownership and governance (Gregersenet al. 2016'1). Henceforth, the EU has committed to implement the SDGs both in its internal and external policies and understood that better regulation will lead to fostering policy coherence in the long run. The SDGs are prominently featured within the European Research Area ERA: "Public authorities at all levels jointly promote consistency between their R\&D cooperation activities and develop joint initiatives that give Europe leadership in addressing global challenges and reaching sustainable

\footnotetext{
${ }^{1}$ Gregersen, C., Mackie, J., \& Torres, C. (2016). 'Implementation of the 2030 Agenda in the European Union: Constructing an EU approach to Policy Coherence for Sustainable Development'. Document de travail, (197). See also: ESIR memorandum https://publications.europa.eu/en/publication-detail/-/publication/4177ae56-2284-11e8-ac7301aa75ed71a1/language-en footnote 26
} 
development goals." ${ }^{2}$ In November 2016, the Commission published "Next Steps for a Sustainable European Future" ${ }^{\prime \prime}$, its Communication on the Sustainable Development Goals

that ensures all coming EU policy measures take on board SDGs at the outset ${ }^{4}$. Designing better regulation tools is a "way to ensure further mainstreaming of sustainable development in European policies", since "all Commission impact assessments must evaluate environmental, social and economic impacts so that sustainability is duly considered and factored in". Furthermore, it is mentioned that ex post evaluations need to analyse "all three dimensions in a strong integrated approach" in the exercise to mainstreaming the SDGs. In this communication, research and innovation is framed as means to implementation of certain SDG targets. Thus, Horizon 2020 is committed to contribute at least $60 \%$ of its budget to sustainable development, with sustainable development being understood as the integration of economic, social and environmental objectives 5 . In the draft (May 2018) of the post 2020 Multiannual Financial Framework the Commission proposes to set the ambitious goal for climate mainstreaming across all EU programmes, with a target of $25 \%$ of EU expenditure contributing to climate objectives. We are witnessing a growing factual commitment to sustainable development in addition to its legally binding embedding in the Lisbon Treaty, thus the SDGs could be further mainstreamed and fostered in STI policies and funding strategies. They have the potential to provide a framework for policies, both horizontally with criteria for funding and evaluation, and thematically, e.g. by anchoring goals and missions.

This brief report gathers relevant information on how the SDGs serve as frame of reference in European research and innovation policies and how the SDGs are emerging and being discussed in countries' and stakeholders' visions of Horizon Europe prior to its negotiation. The central question is how are the SDGs appearing in experts' recommendations and reports, in position documents (and in relation to which topics or instruments), which problems arise from experiences with $\mathrm{H} 2020$ and FP7, what roles are assigned to and foreseen for the SDGs in the next framework programme Horizon Europe?

\footnotetext{
${ }^{2}$ ERA Vision 2020 http://ec.europa.eu/research/era/pdf/era vision 2020 en.pdf

3 http://europa.eu/rapid/press-release MEMO-16-3886 en.htm

4 See also the EU SDG indicator set published in 2017: http://ec.europa.eu/eurostat/documents/276524/7736915/EUSDG-indicator-set-with-cover-note-170531.pdf

5 See: https://eur-lex.europa.eu/legal-content/en/ALL/?uri=CELEX\%3A52016DC0739
} 
Even though the SDGs seem to be present in many connotations of mission-oriented research or the mentioning of grand societal challenges, the objective of this exercise was to explore their visibility both as reference framework or master narrative and as concrete topic in the document corpus. How are the SDGs addressed in the documents? Are they regarded as potential frame for thematic, processual or organisational planning? Are they mentioned as source for monitoring progress and controlling compliance to European visions?

The following chapters will provide evidence on the importance and opportunities but also on the implicitness or even lack of the SDGs in current policy discourse.

For a better understanding of the point of departure for the SDGs in the next framework programme Horizon Europe it is necessary to scan the documents that were influential in the preparation of it. Documenting the design process of the successor of H2020, Reillon ${ }^{6}$ mentions the following papers i.a. as fundamental:

- The European Commission policy briefing on the economic rationale for public R\&I funding and its impact (Oct 2017) link

- The report of the independent High Level Group on maximising the impact of EU Research and Innovation Programmes, LAB-FAB-APP (also known as the LAMY report, 2017) link including a series of issue related briefing papers link

- The foresight study "New horizons. Future scenarios for research \& innovation policies in Europe" (Bohemia Foresight Study May 2017) link

- The memorandum of the expert group on the Economic and Societal Impact of Research (ESIR) on mission-oriented research and innovation in the EU (Dec 2017) link

- The Research, Innovation and Science Expert high-level group advising the European Commissioner for Research, Science and Innovation Carlos Moedas RISE policy brief on "Mission-oriented research and innovation policy (Feb 2018) $\underline{\text { link }}$

- The recommendations provided by Mariana Mazzucato "Mission-oriented research \& innovation in the European Union. A problem-solving approach to fuel innovation-led growth" (Feb 2018) link

Furthermore, we identified several other initiatives, documents and recommendations, amongst them most importantly:

\footnotetext{
${ }^{6}$ Reillon, V. (2018). Preparing FP9. Designing the successor to the Horizon 2020 research and innovation framework programme (IN-DEPTH ANALYSIS No. PE 620.215). EPRS | European Parliamentary Research Service Members' Research Service.
} 
- Expert Group Report "Follow-up to Rio +20, notably the SDGs (2015) link

- The evaluation of FP7 in terms of their SDG integration: several documents from the project FP74SD (2015) link

- Report: "The contribution of science in implementing the Sustainable Development Goals" (2016) prepared by members of the German Committee Future Earth link

- EUROSTAT EU SDG monitoring report (2017) link

- The report prepared by the World in 2050 initiative: "Transformations to Achieve the Sustainable Development Goals" (2018) link

- 2018 SDG Index and Dashboards Report by the by the Sustainable Development Solutions Network (SDSN) and the Bertelsmann Stiftung, link

that provide either valuable insights into the opportunities and challenges of- or recommendations for the design of the new framework programme. Last, but not least we were able to follow several personal and informal debates on the status of the preparation, as well as analysed the

- First public draft of the Multiannual Financial Framework, which sets the scene for R\&l spending (2 May 2018) link

- The Communication from the Commission to the European Parliament, the European Council, the Council, the European Economic and Social Committee and the Committee of Regions on "A renewed European Agenda for Research and Innovation - Europe's chance to shape its future" (16 May 2018) link

- 86 official position papers of member states, associated countries and several stakeholder organisations and initiatives in regard to the next framework programme (see list in annex)

The following sections will report the occurrences of references to sustainable development goals or the Agenda 2030 in those documents and discuss the resulting implications.

\subsection{FP7}

One major objective of the Seventh Framework Programme for Research and Technological Development (FP7, 2007-2013) and in particular its programme "Cooperation" was to realise the 2006 EU Sustainable Development Strategy ${ }^{7}$ and therefore also to contribute to SDGs. A monitoring system was set up to: (i) monitor the contribution of FP7-funded research to EU

\footnotetext{
7 Not all SDG goals and targets correspond directly to the 2006 EU SDS framework.
} 
SDS objectives (accountability), (ii) convey the value of FP7 to the public (transparency), and (iii) foster the governance of FP7 (steering effect) (FP7-4-SD policy brief11). The programme "Cooperation" with a total volume of $€ 32$ billion (out of $€ 50$ billion) funded collaborative research via international and transdisciplinary consortia of academia, industry and civil society in 10 thematic areas. Now, to which extent has FP7 addressed the SDGs, and which areas have been well-researched and which could have deserved further attention? A report from 2015 (part of the FP7-4-SD project) summarizes the findings from programme schemes "Cooperation" and "Capacities": about 2,500 topics in the annual Work Programmes related to one or more of the 17 SDGs, which corresponds to a share of ca. $70 \%$ of all topics and about 5,000 projects with EC financial contribution of about $€ 20$ billion. This share represents ca. $72 \%$ of the EC financial contribution to FP7 research. These figures indicate a genuinely substantial embedding of the SDGs in FP7.

However, results of this study show that several SDGs were receiving more attention than others in research projects, such as sustainable consumption and production (SDG 12), promoting health and well-being (SDG 3), improving cities and human settlements (SDG 13), promoting access to energy (SDG 7) and building peaceful and inclusive societies (SDG 16). On the other hand, goals dedicated to poverty eradication (SDG 1), access to education (SDG 4), gender equality and empowerment of women (SDG 5), availability of clean water and sanitation (SDG 6), conservation and management of ecosystems (SDG 14 and SDG 15), and reduction of inequality between and among countries (SDG 10) were covered only by a relatively small number of topics and projects. The report concludes that the themes health, environment, agriculture (KBBE) contained the highest number of topics related to the 17 SDGs and therefore seem to be the most relevant in FP7.

Within the scope of the FP74SD SDG related FP7 projects were also analysed in terms of their international cooperation (trend towards internationalisation), types of organisation (HEls and private actors accounted for $1 / 3$ of project participation, most PIs came from HEls), centres of excellence (EU-15 had a majority stake in SDG related projects). The report suggests that the SDGs played an important role in the funding of research projects within the collaborative consortium-based programme of FP7. However, the question remains, what kind of visible and measurable contribution or impact these research projects and their results had on the SDGs in the long run. This perspective would require the implementation of an SDG dedicated monitoring system, as demanded by several leading experts (not only for spending on research, but of the implementation of the MFF in general) ${ }^{8}$. Such a monitoring

${ }^{8}$ See i.a. Advisory report by the Multi-Stakeholder Platform on the Implementation of the Sustainable Development Goals in the EU (3/2018) or the Expert Group "Follow-up to Rio +20, notably the SDGs" (2015); FP7 4 SD policy briefings 
system should be linked with other policy monitoring activities to span a coherent perspective across instruments and policies with the focus on SDGs 9 .

\subsection{Horizon 2020}

In Horizon 2020 the SDGs clearly provide a common ground for the engagement and implementation of a transformational agenda:

- Sustainability is promoted across all pillars of the framework programme, however not evenly distributed (more references to the SDG found in the societal challenges pillar). We witness an increase in the Horizon 2020 funds earmarked for SDGsoriented projects, thus rendering Horizon 2020 more aligned with the key priorities of the 2030 Agenda.

- The commitment to spend $60 \%$ on Sustainable Development and 35\% on Climate Change related research is aligned with the Agenda 2030 and beyond. A recent Eurostat report and the further development of SDG indicators provide evidence on the good progress of Europe towards this goal.

- The call for openness (open science, open innovation and open to the world) supports international R\&I cooperation framed by SDGs, however the synergies of openness, knowledge commons and the global intellectual property regime still need to be systematically explored and enhanced further in improving coherent policy ${ }^{10}$.

Most calls in the societal challenges pillar today (Work programme 2018-2020) already require an indication of SDG contribution (some even to quantitative indicators ${ }^{11}$ ), however

\footnotetext{
9 EUROSTAT is working on assembling a system of 100 indicators, which should allow in-depth analysis of the SDG performance of the R\&l activities in the future. However, this needs coherent alignment with funding policies and mandatory instrument requirements. The EU SDG indicator set is the result of a broad consultative process, which Eurostat coordinated and which involved a large number of partners including other services of the European Commission, EU Member States, civil society, academia and international organisations. The indicator set comprises 100 different indicators, evenly distributed across the 17 SDGs. See http://ec.europa.eu/eurostat/web/productseurostat-news/-/WDN-20170707-1?inheritRedirect=true
}

10 See also: Expert Group "Follow-up to Rio +20, notably the SDGs

\footnotetext{
${ }^{11}$ For Horizon 2020 SDG impact we do not yet have evidence on indicator level. See EUROSTAT report 2017 http://ec.europa.eu/eurostat/documents/3217494/8461633/KS-04-17-780-EN-N.pdf However there are more general SDG reports of EUROSTAT. The first in a regular monitoring exercises Sustainable development in the European Union. MONITORING REPORT ON PROGRESS TOWARDS THE SDGS IN AN EU CONTEXT (2017) builds on the EU SDG indicator set that was developed for the purpose of monitoring progress towards the SDGs in an EU context and adopted in May 2017. See: http://ec.europa.eu/eurostat/documents/3217494/8461633/KS-04-17-780-EN-N.pdf The report does not give details about the situation of data coverage in all EU Member States but notes, that there are still lacks of data for some of the indicators. Furthermore, the report and its selected indicators cover only partially STI relevant data and information. Experts call for better integrated monitoring systems that enable the synopsis of
} 
only ex post analysis will shed light on the impact of these measures, whether they are just treated as tick-boxes or if it created enough awareness to further integrate the SDGs into research design and foster their uptake in the future. It is unclear at the moment how and if there will be a dedicated SDG monitoring at least ex-post for Horizon 2020.

The 2015 report of the group of experts Follow-up to Rio + 20, notably the SDGs: "The Role of Science, Technology and Innovation (STI) to Foster the Implementation of the Sustainable Development Goals" lists - inter alia - the following recommendations for RTI policy:

- SDGs should be further integrated into the $\mathrm{H} 2020$ work programs, the research framework programs should be more aligned with the SDGs / Agenda 2030

- Establish science-to-policy task forces under the SDGs with the aim of identifying the need for RTI along the entire innovation chain and identifying target conflicts and possible incompatibilities between SDGs.

- RTI investments should be targeted to potentially transformative projects, programs and initiatives based on high-impact criteria for STI4SD

- Developing an ERA initiative for SDGs.

- Promoting the participation of emerging and developing countries in EU innovation instruments, stimulating the globalization of key EU innovation projects

- Alignment of the EIT mission with the SDGs

Some of the expert group's recommendations can be based on existing strategies and instruments; others can only be implemented in the long term as they are part of a transformation of the overall architecture of EU policies (and new policy coherence for SD). The panel also highlights the potential of the SDGs to act as a vehicle for bringing together conflicting goals, especially when it comes to reconciling interests and focusing on competitiveness.

In addition to the recommendations to improve the SDG orientation of RTI policy, the Expert Group Report provides important information on issues related to

(a) general policy orientations and the need for policy coherence,

(b) communication and information on STI4SD,

(c) EU engagement with international initiatives,

(d) efficient and effective evaluation frameworks of STI4SD,

general innovation, research and SDG indicators. See also the call above for "efficient and effective evaluation frameworks of STI4SD" by the Follow-up to Rio +20 . 
(e) opportunities for specific research to implement the SDGs.

It is vital that EU Member States are encouraged to better integrate the STI4SD perspective in their national strategies and monitoring processes, as well as in their regulatory impact assessments. It is suggested that at EU level monitoring of the SDGs should be integrated or at least better aligned with existing processes, like the "European Semester", as well as the Commission's Investment Plan based on the European Fund for Strategic Investments (EFSI).

\section{3 "New horizons. Future scenarios for research \& innovation policies in Europe" (Bohemia Foresight Study 2017):}

Launched by the European Commission in 2016 the BOHEMIA foresight exercise developed future scenarios for specific contexts of EU R\&I policy. The report describes a range of future scenarios that Europe might be facing in 2040 and suggests ways for research to create the necessary conditions to cope with problems and to prosper. Based on views of experts on a range of issues and topics (such as key enabling technologies, societal issues, policy directions, ....) scenarios were developed that analyse the context of EU R\&I interventions within a global setting. The scenarios are situated between global "megatrends", and the policy goals and values of the European Union. Each of the scenarios stated its relevance to the SDGs.

Governance: $\quad$ Global political and socio-economic context

Biosphere: Climate and Energy / Environment and ecosystems resources and services

Social needs: Health/Security and resilience

Key drivers of change: Accelerating Innovation: people and tech-convergence /Towards a world of cities 


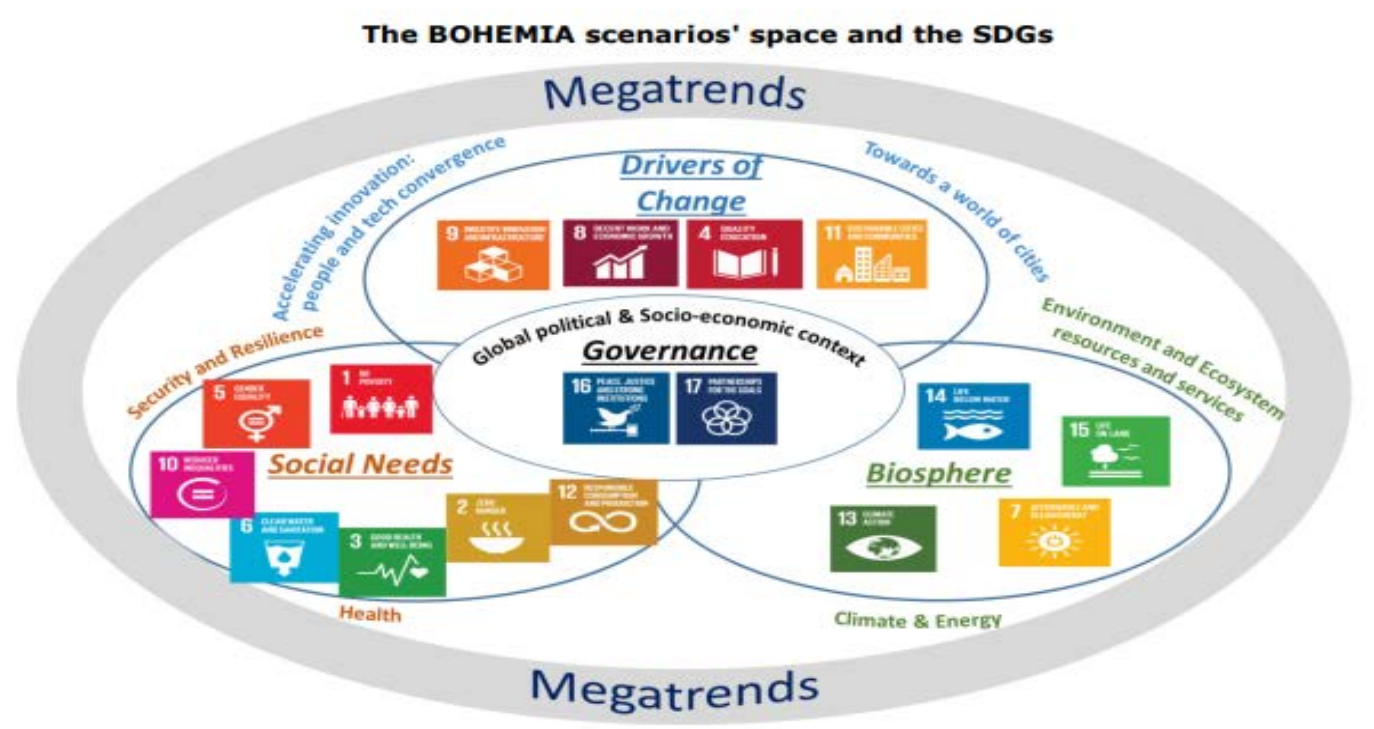

Figure 1: In the figure above each circle represents a category of megatrends containing a set of SDGs. The titles of the scenarios are represented by the curved writing. (Bohemia Foresight Study 2017, p14)

The first phase of the BOHEMIA study contributed to the objective to set the Sustainable Development Goals of the UN Agenda 2030 on top of the EU research and innovation agenda ${ }^{12}$. The SDGs were prominently reflected in the positive scenarios, whereas mostly absent in the negative scenarios. "The positive change scenarios depict what might happen if, as a society, we consistently acted on our values. In these scenarios, we work towards the Sustainable Development Goals. Our leaders act wisely, in the interest of all people. In Europe and globally, we work together. And, due to the fruits of research and innovation, we have the necessary tools to act effectively. In these scenarios, we see Europe as a moral, social and technological leader - punching well above its weight on the world stage, even as its share of global population diminishes" (p10).

The BOHEMIA change scenarios suggest that Europe needs to change its paths and move towards more explorative and maybe even risky forms of research and innovation to create

\footnotetext{
12 See also: https://sciencebusiness.net/framework-programmes/viewpoint/viewpoint-how-foresight-helped-shapehorizon-europe
} 
economic value and societal benefits. Such a transition processes and a change-oriented agenda are to be guided by the Sustainable Development Goals.

Three new types of R\&I are recommended:

- Solutions oriented R\&I: novel solutions for the future challenges that have been identified as critical

- Understanding oriented R\&I: knowledge bases for the future phenomena to be addressed

- Frontier research: not necessarily of immediate economic or societal use, but strengthening of serendipity

Thus, this requires a new mode of programming a research and innovation agenda, with the SDGs as overarching perspective:

- Ensure diversity by calling for a broad range of possible inroads to "solutions- oriented research",

- Embedded transparent scaling and selection process,

- Users/beneficiaries/stakeholders involved at all stages (though to different degrees),

- Much stronger role of programme management in ensuring integration of different activities towards the overarching goal or "mission",

- New approach to monitoring and evaluation (outcome focus) to ensure reflexive and dynamic policy design.

\subsection{LAB-FAB-APP: Lamy report (2017)}

"Over time, performance in science and innovation will determine Europe's place in the world and its capacity to boost the kind of growth that is exemplified by the world's 2030 agenda for sustainable development." (p8)

In its report the High-Level Group on maximising the impact of EU Research and Innovation Programmes chaired by Pascal Lamy highlights the important role of missions to bring more focus to research and innovation addressing global challenges and mobilise different actors, from researchers to innovators. The report further states, that dedication of science and innovation to the grand societal challenges needs to be improved. Over time, European performance in science and innovation will also determine its capacity of sustainable growth aligned with the 2030 agenda for sustainable development, "building a digitally-smart, lowcarbon, energy-efficient and circular economy that offers rewarding work and brings good quality of life for all in liveable cities and countryside; ensuring a safe climate, building a fair society; keeping our oceans clean and productive." (p8) 
The report substantially builds on the Interim Evaluation of Horizon 202013, and concludes that $\mathrm{H} 2020$ falls behind the expenditure target for sustainable development and climate change (p26). Furthermore, the integration of the SDGs into the framework programme calls for improvement of translation and linking high-level objectives with work programmes, calls, and projects. This connection must be made more systematic, transparent and participatory. With the mission-oriented approach ${ }^{14}$, it will be possible to define expected impacts across a portfolio of projects or calls. The experts state that the SDGs should serve "as a global reference framework for defining Europe's R\&I missions." (p15) International cooperation in R\&I will be stimulated by large scale SDG framed missions (p21).

${ }^{13}$ Commission Staff Working Document - Executive Summary of the Interim Evaluation of Horizon 2020, 30 May 2017

14 "R\&I missions should foremost be easy to communicate and capture public imagination and involvement, thus allowing for better communication of the benefits of the future programme (see recommendation 11). They should mobilise many actors and investors, including at national level, and induce action across disciplines, sectors and institutional silos." (p15) 


\subsection{ESIR memorandum on mission-oriented research and innovation in the EU (2017)}

The memorandum of the expert group on the Economic and Societal Impact of Research (ESIR) on mission-oriented research and innovation in the $\mathrm{EU}^{15}$ reminds us that productivity growth does not only have a rate but also a direction and that not all "smart growth is inclusive, nor sustainable" (p5). To understand why Europe needs a mission-oriented approach to R\&l, we need to go beyond the "fixing of market failures" and is about giving directions. Whereas challenges can be defined as broader societal issues and their aims or benefits (e.g. fighting climate change), missions represent more narrowly defined packages or portfolios of activities with "verifiable results on a planned time scale" (p11) achieving

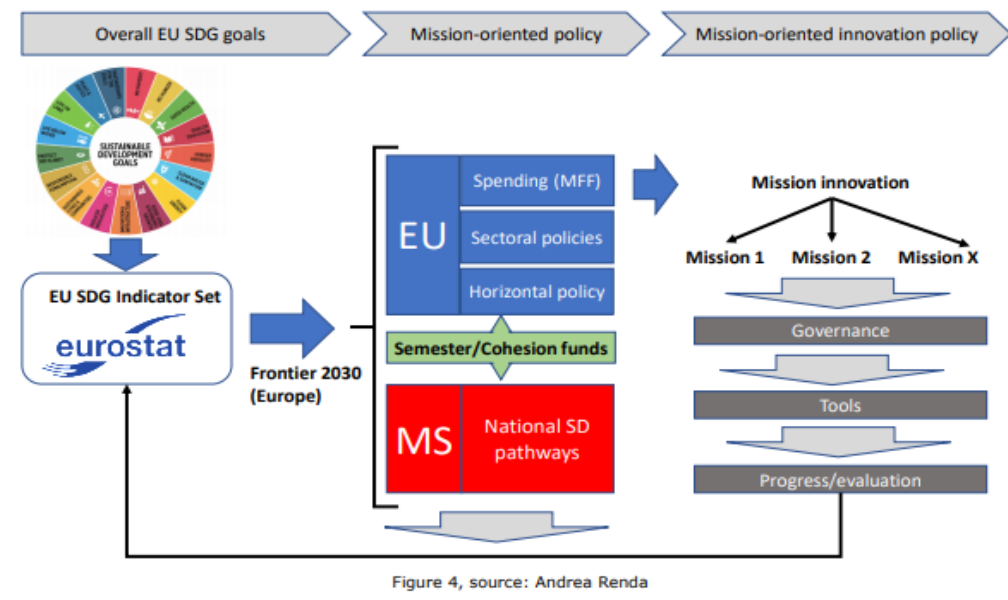

Figure 2 shows the interrelation of the EU and MS level policies activated for a mission-oriented approach.(ESIR Memorandum, p.14) specific results. This entails two important elements: accountability and measurability. To overcome one of the core problems of the Europe 2020 strategy, but also FP7 and H2020, namely using input indicators, such as the GDP as measure of success, mission-oriented policies need to adopt output orientation.

The expert group highlights the SDGs as "clear, at global level democratically chosen set of global societal objectives", which should be extensively used for framing the missions "addressing the big, societal challenges of our times" (p12). Global in nature the challenges for sustainable development need "greater international cooperation, both in finding and implementing solutions including the supply and demand side" (p12).

The report clusters 4 big topics that have the potential to be developed into missions (p14):

- Decarbonisation, and combating climate change;

\footnotetext{
${ }_{15}$ Towards a mission-oriented research and innovation policy in the European Union. An ESIR memorandum - Study https://publications.europa.eu/en/publication-detail/-/publication/4177ae56-2284-11e8-ac73-01aa75ed71a1/languageen
} 
- Developing digital technologies, including Al and cyber-security for better public Services;

- A healthy life at all ages (e.g. lifestyle changes and prevention, affordable care, and controlling deadly diseases such as dementia or cancer;

- Sustainable cities, embracing circular economy and future mobility.

Furthermore, the report differs between Accelerator missions (speeding up progress in a field) and Transformer missions (leading to systemic change) (p15) for all of which the MATURE framework could serve as selection mechanism ( $p 17)$ :

- Measurable

- Achievable

- Transformative

- Understandable

- R\&I relevant

- Engaging

This would require

1. a strong framing towards the SDGs and the further development of measurability and verifiability of impact

2. developing a common EU Intelligence and Foresight based on a common network of EC, EP STOA, and MS;

3. creating a contact point for proposing and evaluating missions

4. generating high-level policy debates both in the European Parliament and Council, involving also the Committee of the Regions in the selection of the proposed missions. (p17)

Most importantly missions require close interaction not only between all three pillars of Horizon Europe, but also across all SDGs relevant policies and activities.

\subsection{RISE policy brief on "Mission-oriented research and innovation policy" (2018)}

The RISE (Research, Innovation and Science Expert high-level) group was advising the European Commissioner for Research, Science and Innovation, Carlos Moedas already on matters of open science and open innovation (Europe's Future: Open Innovation, Open 
Science and Open to the World.) With its policy brief release in February 2018, the group is following the position of ESIR and building on Mazzucato's approach to missions from $2016^{16}$.

In the policy brief the SDGs are not so prominently addressed as in the ESIR memorandum. They are mentioned only once in the annex of the paper. There, the expert group suggests using missions as instruments of science diplomacy to "face the most pressing challenges of globalization: demographic and climate changes, pandemics, natural disasters, cybersecurity, nuclear proliferation among others. Relying on scientific knowledge and innovative technology, it supports the achievement of long-term development, in accordance with the Sustainable Goals (SDG) of the 2030 agenda. Internationalization of science constitutes a powerful tool for growth. Open comparison and competition may lead to greater intrinsic quality, contributing, directly and/or indirectly, to economic development and growth." As a best practice for a mission-oriented science diplomacy the briefing describes the Partnership on Research and Innovation in the Mediterranean Area (PRIMA). From 2018 - 2028 more sustainable management of water and agrofood systems will be developed. In a partnership of 19 countries co-financed by H2020 and participating countries, new R\&I approaches to improve water availability and sustainable agriculture production in a region heavily distressed by climate change, urbanization and population growth will be applied. By addressing a pressing challenge and setting a priority to health and nutrition, issue tackling missions, such as access to clean water and new desalination plants will be operationalised. "It was top-down in vision and strategy, but it will be implemented by means of a bottom-up integrated process" (p17).

The authors of the briefing dedicate a chapter to the important aspect of engaging citizens, which is also highly important for the contribution to SDGs. "In contrast to technology-push policies, mission driven policies focus on the outcomes for society. ... Achieving a mission therefore requires the concerted action of a wide array of players: not only scientists and technologists, but also manufacturers, users, public institutions, policy makers at all levels. In short, a mission-oriented policy requires engagement of all levels of society. Given a mission, whatever it is, and however narrow, we will be unlikely to find a sector of society not affected by it: missions are meant to have large impact. Hence, when we mention the engagement of all levels of society, we do not mean the engagement of representative actors. A mission touches everyone, every person. Engagement therefore does not pass through "representation" but through direct engagement of "all" those concerned." (p11) The authors call for "engagement by design", which includes wide participation in the design of missions.

\footnotetext{
${ }^{16}$ Mazzucato, M. (2016). From market fixing to market-creating: a new framework for innovation policy. Industry and Innovation, 23(2), 140-156.
} 


\subsection{Mission-oriented research \& innovation in the European Union (Mazzucato Paper 2018) ${ }^{17}$}

Mariana Mazzucato was invited to compile a set of strategic recommendations for the next framework programme by the European Commission. In her report the SDGs play a fundamental role, as they are the source and framing for the development of missions.

"Mission-oriented policies can be defined as systemic public policies that draw on frontier knowledge to attain specific goals or "big science deployed to meet big problems". Missions provide a solution, an opportunity, and an approach to address the numerous challenges that people face in their daily lives. Whether that be to have clean air to breathe in congested cities, to live a healthy and independent life at all ages, to have access to digital technologies that improve public services, or to have better and cheaper treatment of diseases like cancer or obesity that continue to affect billions of people across the globe." (p4) The key is to understand and assess impact not on project level but across a domain or a focus area.

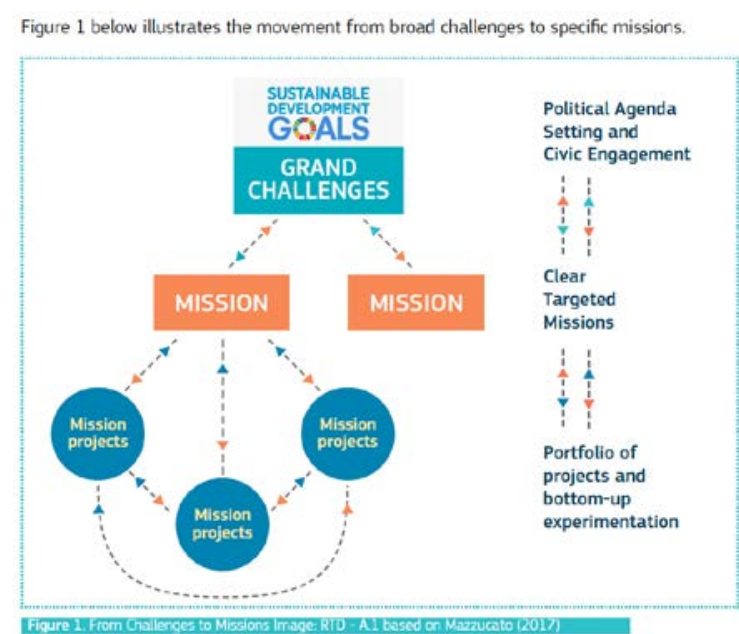

Figure 3 The SDGs as grand vision for the definition (and selection) of challenges and missions (Mazzucato 2018, p11)
Mazzucato draws attention to the opportunity SDGs provide to move forwards with mission-oriented thinking: "They must be taken seriously as both an obligation to future generations and for global prosperity, but also as opportunities to steer investmentled growth. Addressing these challenges, around health and the environment, must not be seen as a trade-off with a focus on economic growth. Rather they present a means to focus on opportunities for investment-led growth - crowding in activity across actors. In addition, targets must be set so that progression to achieving such challenges is as serious as the goal setting itself." (p10)

Whereas SDGs are too broad to be directly actionable, research projects are actionable but only generate isolated or fragmented impact if not linked to broad goals. Therefore, missions are the missing link between the SDGs and concrete research projects. By setting clear and "bold" aims and being backed by a whole portfolio of projects, supportive measures, policy

\footnotetext{
${ }_{17}$ Mazzucato, M. (2018). Mission-oriented research \& innovation in the European Union. A problem-solving approach to fuel innovation-led growth (Recommendations). European Commission.

https://ec.europa.eu/info/sites/info/files/mazzucato_report_2018.pdf
} 
interventions, industry involvement, and measures for success across sectors, missions could ensure systemic change towards the SDGs.

Mazzucato brings several examples, such as "100 carbon neutral cities by 2030", "plastic free ocean", "decreasing the burden of dementia". She mentions the relevant SDGs:

"For example, SDG 14 'Conserve and sustainably use the oceans, seas and marine resources for sustainable development' could be broken down into various missions, for example 'A plastic-free ocean'. This could stimulate research and innovation in means to clear plastic waste from oceans, or in reducing use of plastics, innovation in new materials, research on health impacts from micro-plastics, behavioural research and innovation to improve recycling or drive public engagement in cleaning up beaches." In her report she always links examples such as this with civic participation. This is not limited to research, as in citizen science, but stretches to many different forms of public engagement and participation that have to be defined according to the missions' goals. Mazzucato remarks that missions can only inspire people (and actors in general) if they are part of it.

The selection process for missions should follow transparent and participatory approaches and consider the following principles:

\section{Missions must}

- Be bold and inspirational, with wide societal relevance

- Be ambitious, but with realistic research \& innovation actions

- Foster cross-disciplinary, cross-sectoral and cross-actor innovation

- Set a clear direction: targeted, measurable and time-bound

- Require multiple, bottom-up solutions

Regarding the implementation of missions Mazzucato proposes to re-design current EU funding instruments (e.g. FET flagships) to better align with the SDGs and to better create societal relevance in order to make them part of missions. However, mission governance and management should explicitly differ from other parts of the Framework Programme in order to better align them cross-policy and cross-instruments with grand targets.

Furthermore, she recommends that implementation should focus on

- Engagement of diverse national and regional stakeholders, including broad public engagement, as well as a wide interest from industry and civil society stakeholders 
- Measurement and impact by goals and milestones, but flexible enough to address necessary changes in direction and redefinitions.

- A portfolio of instruments to foster bottom up solutions: portfolio of actions need to encourage multiple solutions and need carefully assembled sets of different funding instruments.

- Flexibility, pro-active management and building in-house capabilities (including training for design and management staff)

\subsection{SDGs in the MFF}

Contrary to the "European Commission policy briefing on the economic rationale for public R\&I funding and its impact" (2017), which does not mention the SDGs, the Advisory report to the European Commission by the Multi-Stakeholder Platform on the Implementation of the Sustainable Development Goals in the EU, of March 2018, highlights the urgent need to learn from the MFF 2014-2020 and to adjust the MFF post 2020 to be more result oriented or sufficiently equipped to underpin the implementation of the SDGs. Only by better alignment and policy coherence for sustainable development can the necessary transformations be realised. The platform recommends a systematic "sustainability proofing" for every Euro spent post 2020. This entails i.a. the

- Adjustment of ex-ante conditionalities as instruments to achieve specific goals

- Ensuring rule of law as precondition for the implementation of the Agenda 2030 and adaption of assessment and suspension procedures of EU funds

- Transformation of the European Semester to a delivery model for sustainability (incl. surveys to better channel EU funding

- Setting of binding expenditure targets (administered by competent authorities)

- Exclusion of contradictory subsidies (e.g. agriculture, fossil fuels) by focusing on hot spots affecting environment/climate

- Clear definition of "EU added value" based on objectives laid down in the Treaty and addition of adequate indicators to European structural and investment funds

- Movement to a evidence based, participatory and simpler approach by i.a. publishing and debating the spending reviews before next decisions

On May 2nd the first draft of the post-2020 MFF was presented. There, the next EU Framework Programme for Research and Innovation "Horizon Europe" is equipped with a budget of $€ 97.9$ billion. Moreover, R\&D funding will also come from other sources (InvestEU, EU Cohesion Policy and Smart Specialisation, European Defence Fund, ITER, Euratom, Digital Europe). Negotiations on the next MFF "should be given the utmost priority, and agreement should be reached before the European Parliament elections and the summit in 
Sibiu on 9 May 2019" (EC communication). Thus, negotiations of the next iterations of the MFF will take place under the upcoming Austrian EU Council Presidency.

In the MFF document the SDGs are not occurring often, however they are mentioned together with important aspects:

- European added value: the EU budget should invest in areas where the Union can offer real European added value to public spending at national level. Pooling resources also means catalysing key strategic investments. Such "investments hold the key to Europe's future prosperity and its leadership on the global Sustainable Development Goals." (рз)

- Single Market, Innovation \& Digital: Cross-border infrastructure: Europe should "better exploit the synergies between transport, digital and energy infrastructure, for example through developing alternative fuels infrastructure or sustainable and smart grids underpinning the Digital Single Market and the Energy Union." (p7)

- Natural Resources \& Environment: A modernised Common Agricultural Policy: Europe will place greater emphasis on the environment (including maritime policies) and climate. "The new policy will require a higher level of environmental and climate ambition by strengthening conditionality for direct payments, consistent with environmental policies, ring-fencing a significant part of rural development funding for actions beneficial to the climate and the environment and introducing voluntary eco-schemes in the budget for direct payments within a performance-based and strategic framework. .... The Commission proposes to continue and strengthen the well-established programme for the environment and climate action, LIFE, which will also support measures promoting energy efficiency and clean energy. To supplement targeted nature preservation efforts, the Commission is also reinforcing the synergies with Cohesion Policy and the Common Agricultural Policy to finance investment in nature and biodiversity. More broadly, in line with the Paris Agreement and the commitment to the United Nations Sustainable Development Goals, the Commission proposes to set a more ambitious goal for climate mainstreaming across all EU programmes, with a target of $25 \%$ of EU expenditure contributing to climate objectives." (p13)

- Neighbourhood \& The World: EU external action: "Stronger coordination between external and internal policies is also needed with a view to implementing the Sustainable Development Goals and the Paris Climate Agreement, as well as the Partnership Framework with third countries on migration. ... Building on the 
European External Investment Plan and its European Fund for Sustainable Development, a new external investment architecture will allow for the "crowding-in" of additional resources from other donors and from the private sector". (p18)

The strategic appearances of the SDGs in the MFF draft demonstrate the willingness to broaden European Contribution to the Agenda 2030 and show the directions, where potential emphases will be set. Within the rationale of the MFF, research and innovation activities are subsumed under "single market, innovation and digital". There is no direct reference made to the SDGs in relation to the outline of Horizon Europe. Research is regarded as important actor and ingredient in the strategic priorities such as Transport, Energy, Digital, Security and Defence. 


\section{European policy stakeholder position statements and comments}

In line with our analytic strategy the central questions are: How are the SDGs appearing in the position papers? Do the position statements address the SDGs as potential frame for thematic, processual or organisational planning? How are they mentioned as source for monitoring progress and controlling compliance to European visions?

The short answer based on the analysis of the 86 position papers is: SDGs are only marginally mentioned in the statements: either they are mentioned as framing vision for Horizon Europe, but not in any more detail, or they are mentioned partly as desirable thematic focus for the missions or challenges pillar in Horizon Europe. The reason for this might be twofold: 1) either the SDGs are already common ground and countries see no further need to explicitly point to them or 2) the SDGs are not regarded as the right framing for a European research and innovation strategy or not suited well enough for European realities and their concurring visions. The next chapter will dig deeper into this matter and explore potential pitfalls and challenges via interviews with experts ${ }^{18}$. The now following sections are dedicated to the analysis of the position statements ${ }^{19}$.

\subsection{Description of document corpus and the method}

We collected 86 position papers (see Annex for list) from European member states or associated countries (30), stakeholders or committees, most of them directly pointed to the shaping of FP9 (72), and some of them responding to the interim evaluation of $\mathrm{H} 2020$ and projecting towards FP9 (10). We analysed the documents in regard to their mentioning of the SDGs and

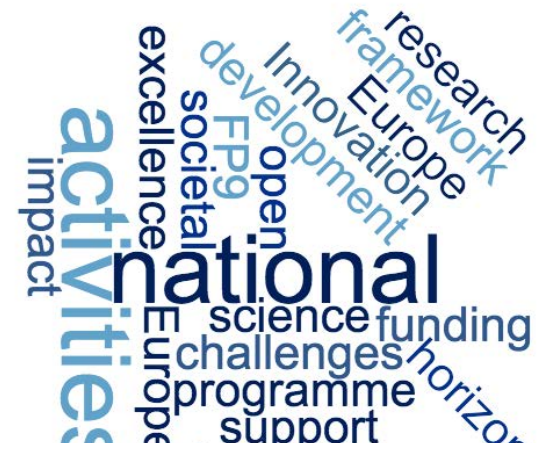

Figure 4 Tagcloud of the most frequent words in the document corpus sustainable development: therefore, we developed a code scheme based on relevant terminology from all 17 SDGs and searched

\footnotetext{
${ }_{18}$ Started on April 23rd 2018 until May 18th and will be documented in the next chapter of this report.
}

19 Most position papers denote Horizon Europe as FP9, therefore we use these terms interchangeably in this and the following chapters. 
through the documents for occurrences and co-occurrences. 41 documents did mention neither sustainable development nor sustainable development goals, nor made any related reference to the Agenda 2030. Two documents mention sustainable development, but without explicit mentioning of the SDGs or the Agenda 2030.

Those, which did not mention sustainable development at all, do however differ widely in their approach: many focus strictly on structural issues, such as the problems of administrative burden, the gap between research-rich and research-poor countries, or the assessment procedures. Often mentioned also in the context of issues of widening participation is the lack of synergies between the Framework Programme and Cohesion policies. Those mostly do not engage in proposing thematic foci for the framework programme.

Countries that repeatedly mention the SDGs and many related sub-topics include: Austria, Belgium, Switzerland, Cyprus, Germany, Denmark, Greece, Ireland, Iceland, Italy, Latvia, Norway, and UK Scotland. Among the countries, which did not explicitly make the reference to the SDGs or Agenda 2030 (Croatia, Czech Republic, Finland, France, Hungary, Lithuania, Poland, Portugal, Sweden, Slovenia ${ }^{20}$, Slovakia, Wales), we still find references to topics or thematic priorities, which could be subsumed under some of the SDGs, such as health, and education, and to a lesser extent climate change and energy ${ }^{21}$. We can see that in these countries infrastructure, industrialisation and economic growth are mentioned significantly more times. Most countries welcome (in different modes of approval however) the introduction of missions ${ }^{22}$ as instrument to improving synergies and allowing sustainable systemic transformations, but these countries do not link this to the SDGs.

\footnotetext{
${ }^{20}$ Interestingly in a personal communication we were informed that Slovenia designed their national policy strategy based on the SDGs, and in the position paper they do not mention them. This shows that the position papers should be taken too literally!

${ }^{21}$ It is important to note that despite the country paper might not include the SDGs in its position, other regional stakeholders, such as the Polish science contact agency, do support the SDGs as reference for FP9.

22 With the exception of Belgium, Czech Republic, Finland, Croatia, Iceland, Lithuania, Poland, and Slovakia that do not mention missions or refer to the mission oriented approach of FP9.
} 


\subsection{The envisioned roles of the SDGs in the next framework programme: stakeholder positions}

From here, we look at those position statements (with an emphasis on countries' positions) that address the SDGs and analyse how they appear in the papers ${ }^{23}$.

There are different types of visions and attributions that could be categorised as follows:

- SDGS as a general frame of reference

- SDGs as thematic resource

- SDGs as processual policy and monitoring instrument

- SDGs in research

- SDGs in innovation

- SDGs in other contexts

\subsubsection{SDGs as general frame of reference}

The majority of mentions treat the SDGs as direct reference to the societal challenges the new framework programme should be focused on, only a few however indicate in more detail which SDGs or which challenges are the most urgent to tackle. A typical quote for the SDGs as frame of reference for the global challenges or missions pillar:

"The Global Challenges pillar must help address the UN Global Sustainable Development Goals (SDGs) in a comprehensive and balanced way, to support Europe's contribution to bringing about an 'inclusive, sustainable, resilient future for people and planet.' The SDGs are closely interrelated and require the contribution of all forms and disciplines of knowledge." (The Guild SSH in FP9 position paper 30b p1)

In 38 documents the SDGs are mentioned as very well suited for setting targets, selecting missions, and creating European Added Value. Furthermore, their central embedding in the next framework programme should serve not only as role model for national SDG contributions, but also as complementation for national activities (e.g. see APRE paper $3^{24}$ ).

Moreover, the SDGs are mostly mentioned in the context of the tackling of global societal challenges, and not so much in the context of the ERC and innovation-based research.

\footnotetext{
23 Numbers refer to documents, please consult the annex.

${ }^{24}$ From now stakeholder and country position documents are references according to the numbering in the annex.
} 
The following countries explicitly mention the SDGs, sustainable development in the sense of the Agenda 2030: Austria, Belgium, Switzerland, Cyprus, Denmark, Germany, Greece, Ireland, Iceland, Italy, Latvia, Norway, and UK (and Scotland). In one way or the other all of them see the next framework programme as key to the implementation of the SDGs, as the only global rational and overarching perspective currently available ${ }^{25}$. Germany highlights the fact that "stronger ties between FP9 and the research- and innovation-related aspects of the SDGs would also highlight the serious ambition to link national, European and international processes more closely than in the past." (63 p13)

Norway would like to see a more active "green shift" and renewal in our societies and economies triggered by FP9. "Green innovation and competitiveness should have priority, as well as the possibilities associated with digitalisation and blue growth for our societies and economies." (78 p2)

Denmark points to necessary improvement of the collaboration and coordination within EU bodies and highlights the strategic character of the next framework programme, which "should be strengthened by a clear focus on underpinning the overall political objectives of the EU, including the possible successor to the Europe 2020-strategy, the sectoral policies, and the European Research Area (ERA) - as well as on the implementation of international agreements such as the Paris Agreement and the Sustainable Development Goals. This requires a stronger collaboration and coordination across different Commission DGs and EU executive agencies." (64 p2)

\subsubsection{SDGs and missions}

The following countries link the SDGs with the mission-oriented approach in their position statements:

- Ireland would like to see the UN 2030 Agenda for Sustainable Development adopted as the preferred framework for selecting missions and setting targets in FP9. (71)

- Austria suggests "a continued and increased emphasis on contributing to solving 'grand societal challenges'. Here, the aim should be to take the global pole position in addressing societal challenges in line with the 2030 Agenda for Sustainable Development. To this end, we need to arrive at real European and better-articulated 'mission-oriented policies' with clearly-defined goals in policy

\footnotetext{
25 Only a few countries mention other global initiatives in that regard, such as: the COP21 targets of the Paris climate conference December 2015.
} 
areas such as health, environment, climate change, food safety and security, social cohesion and European identity, mobility, energy and security" (55 p6)

- Also, Switzerland links the SDGs to the missions: "Switzerland recommends using the SDGs as the reference framework to define the strategic orientation (missions) of FP9, but also to leave sufficient flexibility in the overarching mission descriptions to be able to respond to new challenges as they appear." (59 p4)

- Cyprus is in favour of "exploring the mission-oriented approach, which should meet a

number of requirements. In particular, the missions should: Demonstrate significant European Added Value, building on existing European Policies, such as Europe 2020 and the Innovation Union, while contributing towards achieving internationally agreed objectives, such as the UN Sustainable Development Goals." (61 p4)

- Latvia adds that missions must integrate R\&l, technological development and competitiveness into broader context of sustainable development and economic convergence. (76)

Many more stakeholders link SDGs and missions in their position statements. To sum up the positions do not vary too much, all of them are more or less in line with the documents analysed above, we find the SDGs in the context of missions in relation to:

- The strategic orientation and selection process of missions

- The SDGs could inform improved policy coherence through the missions as instruments

- Guiding the process of sustainable economic growth and competitiveness

The timeline of the SDGs fits well to the orientation of the next framework programme aiming at transformation by 2030: "At EU level, the mission-oriented approach may include some so-called 'moon shots' which ideally should assist in the implementation of the UN sustainable development goals. The time frame for the implementation of the goals is 2030 and hence FP9 is a very important vehicle to drive the underlying research necessary to attaining these goals." (COIMBRA group position $9 \mathrm{p} 4$ )

The Polish Science Contact Agency draws attention to the importance of Social Science and Humanities in regard to the SDGs: "Societal issues are at the heart of SSH (Social Sciences and Humanities) research. SSH also plays an important role in disruptive innovation and social acceptance of science and technology. $\mathrm{SSH}$ research is an important element of delivering a Union of democratic change, which is a central commitment of the Commission. In order to face the grand challenges and to contribute responsibly to the United Nations (UN) Sustainable Development Goals (SDGs), Europe needs these disciplines to fully unfold 
their capacity. PolSCA strongly encourages stronger involvement of researchers from the entire range of SSH disciplines in the next Framework Programme." (43 p2) PolSCA is not alone in promoting the better integration of $\mathrm{SSH}$. Many positions call for more visibility and involvement of SSH.

A few stakeholders, such as UAS4Europe (Universities of Applied Sciences), would like to narrow the scope of the implementation of SDGs to focus just on European Added Value: "The second and third pillar could be restructured to better reflect the needs of both the civil society and the research and innovation community. Given the discussion on the integration of the UN Sustainable Development Goals (SDGs), we suggest to only include those SDGs in the societal challenges in a mission-oriented way that is of European added value." (50 p4) Similarly, the UK suggests that "the United Nations Sustainable Development Goals could form a suitable starting point for identifying possible missions, although participating states should be involved in the selection of missions, and they should reflect European priorities." (86 p4)

\subsubsection{SDGs as thematic resource}

Within the country position statements there are not so many direct references to specific SDGs as potential topics and targets for the next framework programme. However, in the other stakeholders' position papers we find a large number of potential themes addressed in line with their organisations' goals, sometime even with a direct quote of the relevant SDGs.

Italy anticipates that most "societal challenges (SC) of H2020 may find a place in the new framework. However, in co-designing the new FP, the H2020 SC should be re-evaluated and, in that process, in full coherence with UNs' SDGs and with their Sendai Framework 20152030, Italy asks to see included two emerging, undoubtedly major and global challenges, such as Migrations \& Integration, and Disaster Risk Reduction." (74 p5)

Similarly, EMBL reminds us that "Concerning the proposal of transforming FP9 into a more mission-oriented programme seeking inspiration from the United Nations Sustainable Development Goals (SDG), EMBL wishes to highlight that several topics under the $\mathrm{H} 2020$ Societal Challenges have already been considered relevant to the SDG. Introducing a mission orientation in FP9 would thus be a natural extension of the current 'Societal Challenges' pillar" (17 p2). Most countries positions and also most stakeholder papers follow this direction, putting the SDGs at the centre of Pillar 2 - Global Challenges, where they also see the core activities related to the mission-oriented approach. 
However, the question remains how to do this in terms of selection of thematic priorities. The League of European Research Universities LERU proposes to use the SDGs in a bottom-up, implementing the characteristics of FET in a collaborative funding programme. There should be open calls for all SDGs. These open calls should be followed by open consultation processes within the scientific and business communities and integrate also citizens: "The consultation should aim at collecting broad topics, which are clearly aligned to a SD goal and aim at an interdisciplinary and/or cross-sectoral approach. Keeping the topics broad is important to allow for sufficient scientific flexibility and creativity in project applications. The ideas resulting from the consultation process would then be discussed by expert groups (one per SD goal), which are newly established for FP9 and include researchers, business people and policy makers. It is important that each expert group has a good representation of researchers from different disciplines, certainly including the Social Sciences and Humanities. The expert groups should have a clear list of evaluation/assessment criteria to create the final list of topics. ... Each call for proposals should be open simultaneously to applications for projects at different stages of the research and innovation process: Early - frontier research; Medium - 'focused' research; and Advanced - close-to-market research activities. LERU suggests these to be defined as 'research actions', 'research and innovation actions' and 'innovation actions'. The outcome of each call for proposals is therefore a set of projects, focusing on different stages of the R\&I process" (38 p14). This example from LERU demonstrates a similar approach to the missions as laid out by Mazzucato and others (see above). It is mentioned here, as it points to one of the weakest spots within the current discussion of the new framework programme: the participatory aspect in the selection and evaluation of priorities and targets. Even though it is ambitious and certainly worthy of support, we need to ask: How can such processes be governed effectively while at the same time reducing bureaucracy, streamlining and simplifying processes and creating measurable societal impact based on the SDGs? Where can we learn from? What and where is the right institution to manage such processes, and why should this happen just in the context of the societal / global challenges pillar? How could opportunities arising from installing an European Innovation Council provide synergies in that regard?

Our exploration of the document corpus does not shed more light on the governance process for the selection of topics, be it top-down or bottom-up, though it can provide an overview of the themes referred to by the authors.

In the document corpus we categorised thematic priorities as mentioned in the position statements in the latent context of the SDGs - even if they have not been explicitly linked to the SDGs within the texts. From our country document corpus, we can produce a trend of the topics, even though we need to interpret it within the context of the documents, the quest for 
an European Added Value and the broad economic rationale, that we find in most of the country positions.

These documents can only serve as tentative and rather speculative European member states and associated country thematic barometer, however, there is a trend, and this trend shows us that most position statements share similar thematic foci. Most prominently represented is the topic of industrialisation and infrastructure SDG 9 (excluding research infrastructures) with the special focus of re-industrialisation, the visions of "industry 4.0 " and the innovation driven science and technology development and cooperation, next comes economic growth and with lesser emphasis on "decent work" or unemployment as it would be framed in the SDG 8, followed by education SDG 4 (with a special focus on science education and higher education and research training), followed by gender equality (SDG 5) and health (and lesser the dimension of "well-being" as in SDG 3), after which come clean energy (SDG 7) and climate action (SDG 13).

We see a similar trend in the other stakeholder position papers. Here again, matters of industry as well as economic growth outdistance the other topics by far, appearing in nearly all position statements, followed by health, education and climate.

If we understand the priorities of industrialisation and economic growth not so much as SDG related - as in most documents they are not linked with the SDGs at all - but a general rationale, we should instead think about the potential embedding of the SDGs into these objectives. Similarly, we could re-frame the more general and long-lasting objectives of improving education and working towards gender equality, and create a specific perspective based on realms of social systems and societal needs in alignment with a European perspective on the SDGs. The "usual suspects" in terms of SDGs - as they were mentioned often explicitly in relation to sustainable development - are then health, climate and energy, all of which also pose both global and specifically European problems.

Resulting from such an interpretation of the latent content connections in the document corpus we can point to the necessity of clearly defining the SDGs within the European context to better align them to the priority of creating European Added Value on all levels: societal, economic, environmental and for science and research. Not all SDGs depend first and foremost on science and research for their achievement and have to rely much more on the right set of policies and systemic societal change ${ }^{26}$, but since most SDGs are interrelated and

\footnotetext{
${ }^{26}$ See also "COMMITMENT and COHERENCE essential ingredients for success in science and innovation Ex - Post Evaluation of the 7 th EU Framework Programme (2007 - 2013)"

https://ec.europa.eu/research/evaluations/pdf/fp7 final evaluation expert group report.pdf
} 
address cross-cutting issues they are also implicit to the concept of Added Value and therefore need to be monitored closely not to "lose track of which research areas can contribute the most to achieving sustainable development" ${ }^{27}$.

\subsubsection{SDGs as processual policy- and monitoring instrument}

Latvia remarks: "Through its impact, R\&I must foster EU, national and regional growth, address sustainable development goals and serve citizens. R\&I priorities must be better connected to the needs of other sectoral policies and sectoral policies should contribute to financing R\&I and absorbing its results." (76 p1)

Similarly, the Guild proposes that "in addressing the challenges related to Europe's sustainable development we must frame our research, education and innovation in ways that engage wider society and relevant actors (including the public sector, NGOs, industry and SMEs). Our work must serve to reinforce social cohesion and the trust that citizens have in universities and public institutions, and the ethics of rational enquiry and truth-seeking as their core values." (30a p3)

Croatia notes: "...the new Framework programme should reflect the vision of the impact that every action and instrument have on European society and economy. Sustainable development with a focus on global climate change, demographic and socioeconomic trends, public health and national security should be of great importance in the future." (69 p2)

DSW calls for the mainstreaming of sustainable development into FP9. It "should address sustainable development as a cross-cutting issue and set targets similar to $\mathrm{H} 2020$ (60\% of the budget to sustainability-related research). FP9 needs a robust system in place to ensure this commitment is met, given that it was found that H2020 lacks sustainability-related research agendas and a corresponding, effective monitoring system" (13 p1). Likewise, Austria calls for dedicated SDG monitoring measures, however does not explicate the SDGs themselves as policy monitoring indicators, or to monitor policy coherence. Switzerland calls for "sufficient funding should be provided to research that measure the implementation of the SDGs and FP9s contribution to the SDG indicators" (59 p5).

\footnotetext{
${ }^{27}$ https://ec.europa.eu/research/evaluations/pdf/fp7 final evaluation expert group report.pdf p75
} 


\subsubsection{Mainstreaming SDGs in existing strategies and activities}

The SDGs are often mentioned in the context of existing frames, initiatives and roadmaps, such as RRI and ERA. In particular countries express the need to better include the SDGs into ERA.

As part of RRI: Austria highlights the importance of RRI and in particular new forms of participation in a mission-oriented approach to research and innovation, especially when still based on "excellence": "Responsible Research and Innovation (RRI) has enriched the traditional view of excellence in research with consideration of impact and sustainable development, coupled with societal responsibility and institutional change. Solid mechanisms to strategically embed RRI throughout and across future Framework Programmes are required and goals for civil society participation should be considered." (56 p22)

Belgium stresses that RRI should be horizontally integrated for the involvement of "as much as possible all actors of society, avoiding any overrepresentation of the dominant actors of the industry, and be horizontally integrated in the next FP rather than addressed by a separate SWAFS/RRI WP. Although the European Research Area and the European Higher Education Area are two different processes, involving different members and procedures, RRI may provide a conceptual framework that leads to a better complementarity between successor FP and Erasmus + actions in the fields of RRI, Citizen Science, Gender and Open Education." (57 p7)

The European Research Area is one of the most quoted terms in our document corpus as it is regarded as the heart of European R\&I cooperation and an instrument of cohesion policy as well as establishing a coherence, even though the velocities in each country are very different. Denmark asks for FP9 to generate maximum impact by "setting a common, strategic agenda for European research and innovation investments that effectively underpins the EU's overall political objectives and supports the implementation of the European Research Area." (64 p1)

In the ERAC statement FP9 is regarded as keystone in the post $2020 \mathrm{EU}$ political agenda. "FPs and the European Research Area activities are mutually-reinforcing and complementary: promoting free movement of researchers and circulation of knowledge and technology within the EU and beyond strengthens the EU added value of FPs activities. By enabling, joint use of knowledge, methods, infrastructures, staff, and data, they will give Europe the assets needed to attain the Sustainable Development Goals, and position Europe as a committed global leader. FPs also have the potential of creating emblematic successes 
within the EU, as well as contributing to an ever-closer union among the peoples of Europe." (18 p6)

Like several other stakeholders, the Helmholtz Association supports: "Stronger synergies between the next framework programme and structural funds could support this openness. Bridging the gaps between regions more effectively is one of the major political challenges for the coming years, and effective partnerships between research institutions can be one key. This is why Helmholtz welcomes the twinning scheme and has recently launched a European Partnering Initiative creating links between different European regions." (31 p1)

\subsubsection{SDGs in innovation}

In the corpus of documents entanglements of SDGs with innovation related topics is mostly vague or absent. Even though there is a Sustainable Development Goal 9 (SDG 9) with a focus on infrastructure, industry and innovation, we do not find it directly represented in our document corpus (although industry, innovation and economy are very prominently addressed). SDG 9 has the objective of a socially inclusive and environmentally sustainable economic development. In many of the country position papers we see a clear trend towards industrialisation and high hopes for the establishment of new research-based industries and breakthrough developments. We also find a broad understanding of innovation - in contrast to a rather technocentric paradigm -, which is an important prerequisite for future implementation of the SDGs.

Although Poland does not refer directly to the SDGs, the position statement discusses the link between economy and sustainable development and the need to establish a single market for knowledge, research and innovation: "Modern economy is shaped by innovation that is no longer understood exclusively as a new product or service. From the perspective of the European social model and challenges that Europe faces, socially responsible and open innovation plays an increasingly important role in inclusive, sustainable development. ... The future Framework Programme should be a key measure to further develop and promote an integrated European Research Area. Its key political objective should be an even stronger contribution to a genuine single market for knowledge, research and innovation." (79 p1)

Switzerland in particular stresses the importance of the SDGs for innovation and economy: "Take into account of the critical role and contribution of science, technology and innovation in building European competitiveness in the global economy, addressing global challenges and realizing sustainable development. Solutions to food security, sustainable health systems, or innovative ecosystems for agriculture are few examples of the powerful link between sustainable development and science, technology and innovation." (59 p4) 
The statement from Flanders "is strongly in favour of a broad concept of innovation that includes not only technological innovation but also non-technological, social, institutional, organisational and behavioural innovation. Innovation could also refer to new developmental pathways towards sustainable societies, taking account of systemic constraints including societal transformation capabilities. Leaving a wider space for non-technological innovation will encourage cross-disciplinary approaches and involvement of the Social Sciences and Humanities." (58 p35)

Norway would like to see a more comprehensive approach to innovation ensured, "encompassing both technological and non-technological innovation". (78 p1)

Also, in the JRC policy insight publication of the EU Commission it is stated that the "EU industrial and innovation policy should contribute in reversing the rising tide of inequality. A different type of inclusive innovation-led growth is possible in the EU and is in line with economic theory. This could be an opportunity for Europe to overtake competing economies on specific issues by favouring the prioritisation of urgent social challenges such as sustainable 'green' growth." (36 p3)

\subsubsection{SDGs in other contexts}

- Science diplomacy and international cooperation: In the RISE expert paper the SDGs are regarded as perfect science diplomacy instrument. Similarly, in an editorial from January 2018 in the journal Science \& Diplomacy, Colglazier calls for "deep dives" and "action plans" on each SDG, ranging from global to local, incorporating the "ability of science to advise on and evaluate the effectiveness of policies and actions, as well as produce innovations that overcome roadblocks and accelerate progress on all SDGs" (Colglazier 2018: 3). Regarding science diplomacy, the SDGs are mentioned in the document corpus mainly in the context of international development and cooperation, for example Greece states:

"Meeting global societal challenges and responding to international commitments, such as the United Nations' Sustainable Development Goals (SDGs)/COP21 should be the primary goals of international cooperation. Cooperation priorities should also take into consideration developments in other Union policies and fair and equitable dealing with intellectual property rights. Dedicated activities fostering cooperation between the EU and neighbourhood countries, similar to the INCO actions of the 7th FP, are also considered important and we would like to see them included in the next FP" (68 p2). The ERAC statement puts it similarly: "FPs must reinforce the international cooperation with Europe's global partners as soon as possible. The current global context calls for a 
long-standing cooperation between research and innovation actors from all over the world. FPs can boost EU attractiveness and EU positions in decisive multilateral endeavours such as the Sustainable Development Goals and the Paris Agreement." (18 p3)

- SDGs and social science and humanities: many stakeholders, both countries and others - in line with our expert interviews - highlight the importance of SSH to tackle societal challenges. Several countries and stakeholders have even issued specific position papers on the integration of $\mathrm{SSH}$ in the next $\mathrm{FP}^{28}$. It has already been mentioned above, but here again, a quote by the European University Association bringing SSH and the SDGs together: "SSH expertise is crucial in addressing societal challenges involving energy, climate change, poverty, ageing societies, migration or extremism and a better inclusion of these disciplines will expand the understanding of impact and innovation beyond simplistic linear models. Furthermore, tackling the UN Sustainable Development Goals in the next FP requires innovative, multidisciplinary approaches that encompass not only deeper links between Science, Technology, Engineering and Mathematics (STEM) and SSH, but also increased exchanges between different disciplines within STEM and within SSH scientific areas." (22 p4)

\subsection{Blind spots}

When reading and analysing the documents in our corpus, we came across several lacunae in those otherwise very dense strategy papers. It seems the following topics have not received enough attention in relation to their potential for the achievement of the SDGs, but also the opportunities that might arise when adopting the SDGs as a framework or target.

- Excellence and Widening: The SDGs are not put in direct relation with calls for spreading excellence and widening participation, even though capacity building in lower performing countries and regions could profit from thematic directions and (mission oriented) targets along the SDGs (e.g. by enhancing existing pockets of excellence). This could also serve the improvement of Cohesion policies (even though the transfer of funding to the FP is opposed by some stakeholders). The SDGs could become a measure/target to widen the understanding of excellence.

\footnotetext{
${ }^{28}$ See for example: The Guild http://www.the-guild.eu/news/2018/guild-statement-on-ssh final.pdf or the call initiated by Ghent University https://www.ugent.be/en/research/position-papers/ssh-call.htm that was adopted by 11 universities across Europe.
} 
- Co-design and the role of citizens: in the document corpus we do not find many direct connotations of the SDGs and the participation of citizens and communities. Although it has been described as a central and very important element for the successful implementation of a mission-oriented approach according to the SDGs to let citizens take part in the mission, even let them co-design and select the topics, there is very little evidence that stakeholders do actively promote this. It seems everybody is talking about public engagement, but only a few conceptualise actual processes of participation and governance. It is also an open question how wide participation and citizen mobilisation produces impact and can be measured within the SDGs indicator sets.

- SDGs and higher education: Even though HEls all over Europe promote actively the SDGs in their policies, curricula and research, in their position papers they do not emphasize these activities enough. How could FP9 and the SDGs be realised within HEls and the involvement of young students and next generation researchers? How can they be embedded into science education that should be bring research into the classrooms? What about open educational resources, which are hardly mentioned in the whole document corpus (except for Belgium and Flanders statements).

- SDGs and the global commons: fostering sustainable development requires international, supranational, and global resource domains that are common-pool resources. These include natural resources, cultural heritage, cyberspace and to a certain degree scientific knowledge that has been publicly funded. Even though Open Science activities are mentioned in 45 documents, its important link to sustainable development has not been laid out in more detail. Furthermore, only 21 documents mention patents, IPR or intellectual property relevant aspects (mostly not in connection with Open Science).

\subsection{Conclusions}

Questions guiding our analysis of 86 position statements were: How are the SDGs appearing in the position papers? Do the position statements address the SDGs as potential frame for thematic, processual or organisational planning? How are they mentioned as source for monitoring progress and controlling compliance to European visions?

SDGs are only marginally mentioned in the statements: either they are referred to as framing vision for Horizon Europe, but not in any more detail, or they are mentioned partly as desirable thematic focus for the missions or challenges pillar in it. The reason for this might 
be twofold: 1) either the SDGs are already common ground and countries see no further need to explicitly point to them or 2) the SDGs are not regarded as the right framing for a European research and innovation strategy or not suited well enough for European realities and their concurring visions. The analysis of the position papers, as well as the interviews with experts do not give a hint, which reason would be more realistic, probably it is a combination of both, however in the interviews the experts call for specific actions to be taken, to better implement an SDG compatible framework programme.

The analysis of the document corpus - and in particular those statements that include references to sustainable development - demonstrates that

- the SDGs are either regarded as implicit framing of the next framework programme and not given more detailed declaration, or in even less documents their roles and functions are made a bit more explicit, by pointing to their potential for effective action and instruments (as well as monitoring). Compared to the expert and highlevel documents discussed above, the SDGs seem much less relevant.

- the sustainable development related topics mentioned or implicitly referred to most often are health (SDG 3), climate (SDG 13) and energy (SDG 7), besides matters of industrialisation and economic growth (SDG 8 and 9), which were mentioned by far most, however mostly not in the context of the SDGs. All of which pose both global, European and locally diverging challenges.

- matters of monitoring and policy alignment / coherence are important, and that the SDGs need a better integration in ERA

- the SDGs call for a better integration and transdisciplinary cooperation with the social sciences and humanities

- stakeholders in their statements have not considered the relation of SDGs with matters of

- widening participation or reframing the concept of excellence,

- co-design and societal participation, as frequently recommended by the expert policy papers and high-level groups

- fostering and enhancing the potential of HEIs in SDG compliant research and innovation

- global commons, open science and scholarship, international cooperation and intellectual property 
- the SDGs need better alignment with innovation (and technology) driven discourse and rhetoric. Since many country position statements show a clear trend towards matters of economic growth and industry related innovation, and several stakeholders explicitly mention the importance of the alignment of the SDGs with European Added Value, it would be necessary to better embed the SDGs within economic priorities and innovation related instruments and institutions. In our interviews with experts (see next section) we learn about the importance of framing the SDGs as competitive advantage and prerequisite of European Added Value. 


\section{SDG Expert Comments}

To enrich and reflect the analysis of advisory documents, strategy papers and stakeholder positions, we invited nine experts ${ }^{29}$ of sustainable development, who cover a broad range of research fields and have a personal professional history with either the SDGs or/and international/national research policy, as the list in the annex and their comments demonstrate. The first input of the experts was used as framing of the conclusions from the policy papers discussed above. Furthermore, several experts were able to read the proposal for Horizon Europe published on June $7^{\text {th }} 2018$ and comment on it. This second round of experts' comments is collected in the next chapter together with stakeholders' reactions to the publication of the proposal for Horizon Europe in respect to the SDGs ${ }^{30}$. In this chapter we summarise and bundle the topics discussed in the interviews into the following categories:

1. SDGs as framing and guiding vision of Horizon Europe

2. Role and function of universities and HEls for sustainable development in R\&I

3. Monitoring and evaluation of STI in regard to the SDGs

4. Instruments, incentives and best practices for the implementation of SDGs into Horizon Europe

5. (Problem of) Knowledge transfer and capacity building

6. SDG based Innovation

7. SDG key drivers and European leadership

8. SDG related research topics

Since the objective here is to provide a broad, multi-perspectival approach, the chapter is shaped in a narrative style.

\subsection{SDGs as framing and guiding vision of Horizon Europe}

"The last 25 years brought a considerable success in opening up research to societal and environmental concerns", Peter Moser of Montan Universität Leoben says. "It is good that researchers and research organisations are now required to reflect the impact of research, technology and innovation. This would not have been possible without the incentives from the European research funding. Therefore, it is necessary that incentives for contribution to

\footnotetext{
29 For reading clarity we dispense with titles and first names of experts in the following sections.

$3^{0}$ The narrative expert interviews followed a rough guideline for comparative reasons. For the interview guidelines please refer to the annex of this document. Interviews were recorded and partly transcribed and annotated following an inductive coding scheme.
} 
the SDGs are further developed and research impact is better monitored in that regard. It will be of utmost importance that the new framework programme as well as other related policy documents explicitly integrate the SDGs both as conditional framework and as (re)source for the selection of research and innovation priorities." Relatedly, Evelina Santa-Kahle, SDG expert speaking in a personal capacity, says: "The SDGs are a means of policy making and not just an add-on. They provide a good basis for sustainable economies if we manage to translate them into European contexts - always with a global perspective and the claim to multilateral agency."

Ute Stoltenberg of Leuphana University Lüneburg reminds that sustainable development is not "programme ready", rather a social search, learning and design process. The necessary rethinking, thinking in global contexts, understanding of the complex relationships is a task for all people, who want to participate in shaping their own lives, in responsibility to nature with all the creatures that life on this earth from kindergarten to adults in the various fields of social activity. The big question is: how to co-design and incentivize this participation?

Nebojsa Nakicenovic of the International Institute of Applied Systems Analysis IIASA also addresses the incentives and calls for a better understanding of the requirement of systemic change: "The SDGs represent a new social contract for the world. However, they need systemic change, which will not be induced by penalties or stick-based approaches. We also need incentives to change the values substantially. SDGs require a good governance and balance of bottom-up and top-down approaches. The best thing about them is that they are "for the people": easily understandable but not so easily accountable. Politicians and administrators need to understand that the SDGs are not just representing a "green agenda", and that they focus on our socio-economic life as well."

Dirk Messner, former director of the German Development Institute DIE, warns of continued technocratic imbalance: "Since many years we are witnessing that innovation and technology are regarded as the main and most important drivers for sustainable growth, whereas the Agenda 2030 and sustainable development as well as the social sciences and the humanities seem to always come downstream. We need a better balance towards social innovation that includes institutional and technical innovation. Without that it will not be possible to create the right incentives for systemic change and the sustainable transformation of life styles in line with the SDGs. The SDGs represent a multilateral agreement, so they are well suited to serve as basis for global cooperation (far beyond the context of international development and cooperation). The SDGs are a political agenda and their strength is to go substantially beyond the current practice of quick technological fixes." 
André Martinuzzi of the Vienna University of Economics and Business notes that it was very good that the three pillars of Horizon 2020 obeyed other logics, audiences, and governance mechanisms and he warns of a merging of pillar 2 and 3, which is foreseen for Horizon Europe. "With distinct pillars for Societal Challenges and Industrial Competitiveness, diverging or competing objectives might also be reconciled. Though if we think about the continued dominance of the Lisbon objectives on sustainability objectives for example, and if the grand societal challenges are dominated by a purely economic logic, this will lead to a development that benefits neither the SDGs, nor civil society, nor, ultimately, the idea of more public engagement - on the contrary. Those aspects could only be supported through a significant strengthening of RRI, SSH and civil society, but that would have to go far beyond the rather vague idea of the missions." Helmut Haberl, social ecology expert of University of Natural Resources and Life Sciences (BOKU), also points to the problems of the dominance of an economic logic: "Many researchers still struggle with the transition from FP7 to H2020, as the political objectives narrowed down to mainly support economic growth. Furthermore, there were new evaluation procedures established, many of them delegated to consulting companies, plus direct application of research and the focus on commercially exploitable products became a central criterium for evaluation. There should be more to responsible science, science with a social mission, than just working to invent new products for industry."

All experts generally agreed that the SDGs should have a prominent role in the next framework programme, both as grand vision and framing, as well as providing orientation to concrete research and innovation priorities. However, besides being a good resource for research and education policy making, they bring about several challenges, which will be discussed in the next sections.

\subsection{Role and function of universities and HEls for sustainable development in R\&l}

Stoltenberg brings to mind that "The role and power of universities as drivers for sustainable development is not at all fully exploited. They have a special standing as long-term partners for long-term processes, compared to limited, project based endeavours or initiatives. Their transformative potential however, has yet to be unleashed by implementing more transdisciplinary and interdisciplinary learning and research activities. Furthermore, by creating spaces for exchange or cooperation with socially and ecologically responsible companies and industries, universities could enhance innovative teaching and research practices. Last, but not least, universities are themselves spaces for the participation of youth and young generations, for whom the SDGs are important topics and objectives. They have moreover - the potential to act as access points for citizen involvement in the setting of the 
research agenda, as well as the evaluation of research results for social and environmental impact."

A Min Tjoa, Vienna University of Technology, agrees: "We need to strengthen the roles and functions of the SDGs in education and training. ERASMUS could be such an existing structure within which this could be done. Universities have to be better included and mobilised for the SDG agenda. Tjoa welcomes dedicated chairs for sustainable development, but remarks, that the SDGs need to be mainstreamed across all themes and curricula, like at TU Vienna in the field of architecture and construction."

Inter- and transdisciplinarity are still problematic - both in a paradigmatic as well as in a structural/institutional sense: "Universities are still organised along the silos of disciplines. Therefore, it is important to initiate incentives and opportunities for cross-disciplinary and truly socio-technical research and innovation endeavours", says Messner. Global cooperation helps to build bridges not only between institutions but also between research fields. The SDGs could serve both as incentive and as resource: Tjoa introduces the ASEANEuropean Academic University Network (ASEA-UNINET) that was founded in 1994 and today consists of around 80 universities in 20 countries. The university network aims to promote research and teaching activities between member universities in Europe and South East Asia (Indonesia, Iran, Malaysia, Myanmar, Pakistan, Philippines, Thailand and Vietnam) and SDGs are a priority research theme there connecting several research fields with each other.

Within the strategic development of $\mathrm{HEl}$ and research organisations, sustainable development in general and the SDGs in particular can function as orientation or guiding principles. Martin Gerzabek, University of Natural Resources and Life Sciences (BOKU), points to the prominence the SDGs hold in the university development plan for the BOKU as well as in several other universities, and to the Austrian Alliance of Sustainable Universities ${ }^{31}$. Founded in 2012 as an informal network of universities the alliance aims at promoting sustainability issues in Austrian universities. Therefore, it follows the objectives to exchange best practice experiences and to initiate joint activities related to the SDGs within research, education, operations, knowledge transfer as well as strategy building, to anchor sustainability issues at universities and thus to contribute to a sustainable society.

Moreover, Gerzabek points out how important such alliances are on national level: "On national level there should be university alliances, similar to that one in Austria. Each of the participating universities could take the lead for one- or for a bundle of SDGs, cooperating on their alignment and better implementation. Furthermore, they could learn

31Plattform Nachhaltige Universitäten http://nachhaltigeuniversitaeten.at/english/ 
from each other in regard to assessing impact and SDG related knowledge transfer."

Furthermore, Gerzabek calls for more openness in education: "Another important aspect for the fostering of SDGs in academic context is the creation and recognition of open educational resources for this topic. BOKU has developed several open educational resources for quality education on SDGs, which are now shared internationally and help to spread the knowledge and instruments necessary." Finally, Gerzabek draws attention to the benefits for HEls contributing to the SDGs, "All research institutions should be encouraged to study the SDGs systematically. The BOKU initiated a cross-university platform "Zentrum für Sozialen Wandel und Nachhaltigkeit" ${ }^{22}$, an informal network for cooperation and mutual learning. This was also done to be well prepared for FP9 and the many societal challenges ahead."

Similarly, Moser remarks that the SDGs are a great opportunity to develop University strategies and performance plans, especially if we aim at making universities fit for the industrial future of Europe, job creation and innovation driven sustainable growth.

Summarising the expert positions, HEls roles and functions in the implementation of sustainable development in research and education, but also as spaces of participation and civic mobilisation are still not developed enough. Universities should use the SDGs both as driver and strategic principle to expand and foster their important position as long-term and robust player in the research and innovation fields.

\subsection{Monitoring and evaluation of STI in regard to the SDGs}

"Until now we lack a concrete system to measure impact of research and innovation on sustainable development. Many stakeholders are currently developing such indicators, but we need a system suited for European contexts and added value. Even more, such a system should be implemented and extendable from the start of the next framework programme", Santa-Kahle recommends.

Martinuzzi points to the monitoring system established by in the service contract 33 , which was unfortunately not prolonged in Horizon 2020stopped: "There is nothing similar for $\mathrm{H} 2020$, which has the same level of detail, combining such a broad range of data and information-scientific instruments, e.g. to study types of cooperation. Information like this will be crucial to plan missions and optimise funding instruments; however, there is no system in place that could provide this for H2O20 or beyond." Experts agree that such a

\footnotetext{
${ }^{2}$ https://www.boku.ac.at/wissenschaftliche-initiativen/zentrum-fuer-globalen-wandel-nachhaltigkeit/

33 https://www.FP7-4-SDG.eu
} 
monitoring system would be absolutely necessary for FP9, also to enhance the knowledge transfer within and between European organisations and Member States.

Moser also calls to attention that - because systemic change and sustainable societal development is urgently needed - we should thus establish robust instruments and institutions that have the capacity to monitor this change, such as the IIASA. Tjoa adds relatedly: "IIASA could be established more centrally in this regard, as well. They already have several means to monitor the development of research and innovation along the SDGs and social impact on a systemic level."

Nakicenovic, as IIASA representative, calls for a more holistic approach and one that IIASA is pursuing: "As the Agenda 2030 states, there should be no one left behind, also no SDGs should be left behind. IIASA aims at establishing an interdisciplinary SDG research field, which also makes it possible to analyse several SDGs together or along each other, measure their impact on each other in different context, and also the conflicting interests between SDGs. Furthermore, research needs better models to bring together global and regional approaches and data."

Gerzabek also addresses the potential role of IIASA and emphasises a "learning by doing" approach: "We do not yet have sufficient monitoring tools, so we need to learn by doing. The BOKU initiated a cross-university evaluation of the contributions to sustainability voluntarily. From a systemic point of view, it will be more and more important to develop proactively the adequate monitoring instruments that can help to analyse synergies and limitations of SDGs and related policies and regulations. The IIASA could play an increased role hereby and would be well equipped to perform as hub for knowledge transfer between research and politics. The role of IIASA should be strengthened." In the opinion of some experts IIASA could take on the role of such an important intermediary actor. However, based on this exemplary outline of the necessary profile, it remains to see what other roles and functions such a knowledge hub should take over.

Furthermore, Martinuzzi points to the importance of a monitoring system for understanding the impact of STI funding policies. "Since FP7 we are witnessing transformation of sustainable development from individual topic into a cross-thematic priority. However, there was broad concern that this might reduce the visibility or even the impact of the sustainable development thematic. The project FP7-4-SD linked topics of research funded under FP7 with the targets of the SDGs from the programmes "Cooperation" and "Capacities". Although it cannot be generalised to FP7 as a whole, the analyses carried out at the end of FP7 demonstrated that about 70\% of all topics within these programmes were related to one or more of the SDGs." Under these topics about 5000 projects were 
carried out with EU contribution of about 20 billion Euro. The study demonstrated a positive effect towards the SDGs even though sustainable development became a cross-thematic.

Santa-Kahle and Martinuzzi draw attention to the problem of SDGs as sources of potential conflicts of interest e.g. in resource allocation or in opposing objectives between the

SDGs. Martinuzzi points to the need of a monitoring system in order to optimise instruments and incentives: "Negative impacts are still blind spots. It is very delicate how to best communicate such negative impacts e.g. job losses caused by new technologies such as industry 4.0 and digitalization on the job market. However, we need to learn from them in order how to optimise our funding instruments and to anticipate unintended or collateral effects of R\&I funding." More in general, Martinuzzi remarks that we need to learn more "what causes negative impacts on is bad for the SDGs, and if there is research and innovation that is counterproductive towards the SDGs, even more about the trade-offs between the SDGs." He asks: "What about the negative effects of R\&I funding? Innovation brings growth and growth brings employment - is that true? How open and transparent can monitoring and learning about the effects of our R\&I activities be?" Furthermore, "how transparent can decision making in regard to the allocation of resources be?" In the FP7 ex-post evaluation report Martinuzzi et al. recommended to combine the current initiatives for agenda setting and stakeholder involvement in a transparent and participative sub - programme dedicated to "Visions and Agendas" 34 . Even though agenda setting and the design of work programmes followed well established routes and procedures already in FP7, and also in $\mathrm{H} 2020$, concerns there was a lot of concern regarding about transparency and stakeholder involvement remained. How much of society relevant topics and themes were was really in the concrete calls for the Societal Challenges pillar in H2020? R\&I need to be brought closer to society, to citizens and their needs. "Citizens and stakeholders should be engaged in a dialogue about the purpose and benefits of research and the way it is conducted. This entails the development of incentives for science communication as well as the establishment of particular support for more strategic measures of communication with different audiences." (Martinuzzi et al. 2015, p 23) This will be the big challenge for FP9. How to organise such processes a new? How to find the right governance structures and qualified reviewers?

34 https://ec.europa.eu/research/evaluations/pdf/fp7 final evaluation expert group report.pdf page 9, 23, 70. Fresco, L. O., Martinuzzi, A., Anvret, M., Bustelo, M., Butkus, E., Cosnard, M., ... \& Nedeltcheva, V. (2015). Commitment and Coherence. Ex-Post-Evaluation of the 7th EU Framework Programme (2007-2013). 


\subsection{Instruments, incentives and best practices for the implementation of SDGs into FP9}

In Horizon 2020 the SDGs were not linked explicitly enough to the societal challenges. Only slowly change is happening, since this year alignment with several SDG related indicators is required, even though ex-post. The biggest problem for Gerzabek is the lack of a systemic approach. In Horizon 2020 problems are still regarded from sectoral perspectives. There is not enough cooperation and joint problem solving, because this would require designing such interfaces and the global context into the research programme from the start. For Horizon Europe Gerzabek suggests a more global perspective taking into account the responsibilities Europe has towards the world. "We need more incentives, such as prizes for sustainability, e.g. like the land and soil management award of ELO. Joint programming initiatives would trigger more engagement of country level", Gerzabek notes

Tjoa wants to maintain excellence as most important evaluation criteria for research; however it should be broadened to aspects of sustainability. There should be specific boni for application orientation with regard to the SDGs. Contribution to the SDGs needs to be rewarded with dedicated points / evaluation advantages.

Haberl reminds that "excellent science can also have social missions and pursue social goals. Curiosity driven research can also have a social mission, in the ERC we see that this is working very well. Excellent interdisciplinary science is needed as a foundation of sustainable development. However, it can only become a solid foundation, if it is recognized and evaluated on a level playing field with disciplinary research [...]. There should be structures in place with the capacity to evaluate excellence in interdisciplinarity, e.g. panels. Current structures in some programs are not well designed to evaluate interdisciplinary proposals, as the evaluation criteria are mainly suited for classic "disciplinary" projects. In current structures there is often not enough time for discussions on interdisciplinary projects, and there are not enough reviewers that have experience in this. Decision structures have to be redesigned.

Nakicenovic states: "Horizon 2020 still acts to "sporadic" and focuses its programmes on single SDGs. This has to change in FP9. We need missions oriented to bundles of SDGs with very specific objectives. [...] Experiences with the Joint Research Centers JRC might serve as basis for the development of new instruments." Nakicenovic complains that Europe does not have a chief scientist anymore. On international level this is regarded as problematic since the SDGs are also a matter of science diplomacy at highest level and there is no contact point anymore in Europe. 
Countries need roadmaps, either dedicated to the SDGs or with the SDGs embedded in manageable policy goals. Nakicenovic lists best practice examples for that:

- Sweden has its innovation policy under the SDG umbrella https://sustainabledevelopment.un.org/content/documents/16033Sweden.pdf

- Japan has a dedicated SDG Implementation plan: http://www.mofa.go.jp/files/000252819.pdf

- Germany follows a national SDG strategy: https://www.bundesregierung.de/Content/DE/ Anlagen/2017/02/2017-02-27nachhaltigkeit-nevauflage-engl.pdf? blob=publicationFile \&v=1

Furthermore, Nakicenovic points to China that is currently developing an SDG related strategy within its "One Road One Belt" vision" with a financial frame bigger and more impactful than the Marshall plan".

Moser emphasises his very good experiences with the KIC - knowledge and innovation communities instrument of the EIT. Even though it takes a considerable time to bring together the right consortium, governance structure and to write the proposal, it brings not only increased capital flows towards its goals (in the case of the raw materials KIC around 100 Mio Euro), but new and strong networks of cooperation. The KIC could serve as best practice for the improved implementation of the SDGs into funding and research cooperation instruments. Moser reports how the participation in the KIC Raw Materials 35 brought a new drive and spirit to the whole university. He says, the art is to combine deep understanding of technology with a broad perspective on socio-economic and environmental aspects of this technology from the beginning. The KIC supports this position and gives enough space and time to consider societal and environmental challenges in their full scope. The cooperation of such diverse actors from research, education and industry makes this breadth possible. Partnerships that evolved during the $\mathrm{KIC}$ will most likely carry on beyond the completion of the KIC.

Nakicenovic further mentions "The World in 2050" TWI205036, a global research initiative launched by the International Institute for Applied Systems Analysis (IIASA), the Sustainable Development Solutions Network (SDSN), and the Stockholm Resilience Center (SRC). The initiative brings together a network of leading policymakers, analysts, modelling and analytical teams, and organisations from around the world to collaborate in developing

\footnotetext{
35 https://eitrawmaterials.eu

${ }^{36}$ www.twi2050.org
} 
pathways toward sustainable futures and policy frameworks needed for implementing the SDGs, and more importantly, for achieving the needed transformational change.

Messner refers to the Future Earth ${ }^{37}$ initiative as example how stakeholder processes and negotiations could be organised in order to have an impact on policy making. Driven by research and innovation actors from around the world, latest research findings are transferred to government, business and community decisions and policies. For example, the Global Carbon Project's annual projections of greenhouse gas emissions, have helped to shape the targets of the Paris Agreement on climate change ${ }^{38}$. Similarly, there is now a platform in Germany dedicated to monitor and advice the implementation of the German Sustainability strategy ${ }^{39}$. The objective is to develop research driven recommendations for politics as a research network, think tank and dialogue forum. The Steering Committee of the platform is made up of 26 leading representatives from science and society. Since there are already many research activities for each of the 17 sustainability goals in Germany, the platform should help to connect this knowledge more closely and to prioritize objectives. One of the core question of such a platform is how to organise its inherent pluralism despite its norm-driven approach and how to create a productive governance. The main task is to tackle specifically the most delicate and complex problems, those where we do not progress enough.

Stoltenberg emphasizes matters of participation for the success of the SDGs in a missionoriented framework programme: "The participation and active involvement of civil society and communities will be clue to the contribution to the SDGs for long-term systemic and structural change. We cannot proceed with a top-down approach that "teaches" civil society how to behave. We need to take more into account the concerns and practices of citizens and communities, especially those of youth." How this participatory agenda setting, research, and evaluation procedures will be organised will be a big challenge. There is need to better involve HEls, but also civil society organisations (CSO).

Size matters: "Moreover, the inclusion of civil society organisations in agenda - setting at the highest levels of FP formulating is likely to be the most efficient way to include their values, norms, insights, knowledge, and influence. This kind of change could alter the character of FPs, such that collaborative research, centred on socially relevant areas, would be incentivised.", says Martinuzzi. Evidence shows that the integration of CSO and other civil society stakeholders works best with smaller project sizes ${ }^{40}$. This rationale goes against the trend to even bigger projects and missions. It is also a problem for social sciences and

\footnotetext{
37 http://www. futureearth.org/

${ }^{38}$ Paris Agreement

39 https://www.iass-potsdam.de/de/forschung/thema/wissenschaftsplattform-nachhaltigkeit-2030

${ }_{40}$ Martinuzzi et al. 2016: http://ec.europa.eu/research/swafs/pdf/pub_public_engagement/ki-04-17-578-en.pdf
} 
humanities since those fields are less coherent and more fragmented than techno-sciences, Martinuzzi remarks further.

On a global level, as well on national level experts mention several initiatives and networks as best practices, such as university alliances for sustainable development, and international platforms to enhance knowledge transfer between research, policy and innovation. Experts do not know of any best practices on EU level, but point to several funding and cooperation instruments, which could be built upon for the design of SDG related and more participatory STI activities that have the potential to bring about or foster systemic change, both in the ways research is done, and how its impact is handled and evaluated: JPIs, JRCs, KICs, to name a few. Instruments will also determine which stakeholders and research fields can be productively involved. We learn that the bigger the project sizes the harder for CSOs but also for Social Sciences and Humanities to participate.

\section{5 (Problems of) Knowledge transfer and capacity building}

One of the biggest general problems - mentioned by several experts - is the lack of - or insufficiency of knowledge transfer within European policy bodies, between them, between EU and member states, and often also within member states. They call for powerful instruments that allow for a pooling of results and for broad transfer to the relevant stakeholders. Only then can we sustainably build on the results of research and development funding and translate it into innovation. Santa-Kahle is envisioning a sort of inter-service consultation mechanism, similar to what has to be developed for a mission-oriented approach. Similarly, Martinuzzi notes: "The Better regulation initiative is an important instrument to assess the outcomes of EU policies. Although it is not enough to cope with the lack of knowledge convergence and synthesis. It needs better strategic intelligence instruments and knowledge hubs, which are able to bundle the knowledge produced with European R\&I funding. This is a lively system that needs curation, not only simply saving the information in a cloud. There are no central contact points, even if there is a unit, it does not mean the information is well understood, summarised and ready for learning from it." Such a pooling of knowledge is the necessary prerequisite for the implementation of an SDG based framework programme.

Messner draws attention to a particular deficit in knowledge transfer: "Transdisciplinary research has lately gained more attention and also more funding from the EU. This is good, but now we must develop adequate participatory methods and instruments. We also need more participatory and dialogical instruments to close the gap between global analysis highly aggregated and assessed - and regional and local solutions. This dichotomy 
between globally integrated assessment analysis and locally very diverse problem solving produces a big deficit. We need a holistic European perspective that integrates this dichotomy and turns it into benefits for regional research and actions. This would help to avoid "ex-post repairs" and end-of-the-pipe politics and bring about a valuable knowledge base that could be further used for decisions on the distribution of resources and the setting of priorities."

"Societal impact must be evaluated by societal actors", says Martinuzzi and calls for more involvement of civil society organizations and societal actors in the evaluation the societal impact of research proposals and projects. "We need more capacity building for the qualification of reviewers and evaluators, especially if we want to involve civil society organizations. I would therefore recommend rethinking and offering capacity building for citizens and civil society organisations ${ }^{41}$ ? We need better instruments and long-term structures to foster the participation of civil society stakeholders", he says.

\subsection{SDG based Innovation}

Innovators and industry have taken part in the writing of the Agenda 2030 as well as the formulation of the 17 SDGs. This demonstrates commitment to change for sustainability, which now has to be incentivised and fostered in the right ways. Haberl points out that "Orienting the research framework primarily towards economic growth has not delivered until now and is in my view not a good way forward. A lot of money has been and is being spent on innovation, also in many programmes of the European Union. But we need other types of innovation, e.g. social innovation. We urgently need innovation that does not come in the form of products."

In Moser's opinion, we need an even stronger cross-cutting focus on circular economies, a concept that offers many opportunities for European added value in line with the SDGs: "For example, future key technologies will be built from a more complex and varying composition of raw materials, which calls for designing sustainability into raw materials cycles from the beginning. Low-carbon requires a circular economy to supply and re-cycle from primary resources. Key to a sustainable industrial base and economy is resilience that takes planetary boundaries and societal challenges into consideration."

\footnotetext{
${ }^{41}$ http://ec.europa.eu/research/swafs/pdf/pub_public_engagement/ki-04-17-578-en.pdf Martinuzzi, A., Hametner M., Katzmair, H., Stahl, B., Dimitrova, A., Lorenz, W., More-Hollerweger, E., Wurzer, G., Chung, C., Gulas, C., Schroll, G., Werdenigg, A., Rainey, S., Wakunuma, K., Network Analysis of Civil Society Organisations' participation in EU Framework Programmes, Vienna \& Leicester, 2016.
} 
Gerzabek calls for better understanding of SDGs benefits: "Policy makers, researchers and innovators need to understand that we can become innovation leaders WITH the SDGs. SDG compliance should be treated as asset instead of a burden. Only then can we achieve a systemic transformation without leaving anyone behind." Messner also sees the urgent need for resituating the public discourse: "It will be important to reframe the rhetoric and the narratives towards establishing the SDGs as competitive advantage to European stakeholders, as well as motivators for disruption and breakthrough innovation."

In line, Tjoa asks: "How can we bring industry back to Europe and strengthen existing industries in regard of their SDG compatibility? How can we turn the SDGs into an asset for socio-economic players? Within the EIC (in cooperation with the EIT) a central information hub and contact point could be established that is responsible for the implementation of the SDGs into research and innovation agendas and for monitoring effects of funded research and innovation. All funded activities must not be harmful to the SDGs. The SDGs need specific instruments for their implementation and monitoring. The SDGs need to become a competitive advantage and part of the leading edge of technology development. They also need to work with economic value chains, comply with economic thinking."

In line with many of the stakeholder documents analysed in the sections above, the experts call for a broader understanding of innovation, including social innovation. However, some address the need to make the SDGs fit for socio-economic logic, and to turn them into assets, competitive advantages and guiding principles for innovation leaders. Tjoa mentions explicitly the European Innovation Council EIC as potential place to host an SDG related knowledge hub and monitoring system, in that regard it could also function as capacity building hub for the evaluation of societal impact of STI funding.

\subsection{SDG key drivers and European leadership}

Santa-Kahle notes that the implementation and mainstreaming of the SDGs need more involvement and pressure from the European Parliament and the Member States. The SDGs should become a high-level priority only then can they enfold their multilateral agency. The leaders of states need to ask the right questions: which type of mobility do we want to promote; which types of agriculture should be further developed for future generations? Following Santa-Kahle it is necessary that policy makers understand new and alternative forms of growth and sustainable economies, and refrain from just designing add-on policies that try to fix market behaviour. In her opinion, we do not see enough political will across Europe to really implement the SDGs right now. 
Similarly, Tjoa says: "The European Parliament and Member States need to be more pushing for an SDG relevant research and innovation agenda. The UNO, and other big agencies, such as the energy agency in Paris need to act even more as pushers/drivers." G20 and G7 play an important role; similarly, the World Business Council for Sustainable Development could be regarded as best practice in SDG related innovation strategies. Regions and cities need to raise their voices more, because the SDGs provide a lot of opportunities for them, also in terms of research and development, recommends Nakicenovic.

Stoltenberg says: "There is not only one road to sustainable development in Europe, but there is a European responsibility which needs to be better defined!", and she calls for better and more systematic analysis of Europe's potential contributions to the SDGs on a 1) global and on a 2) European level:

1) Global level: We need more systematic analysis how Europe can contribute to the solution of global problems. From that we should develop several priority fields of action, where Europe can contribute best.

2) European level: building on the experiences with previous and running research and innovation activities, we need

- to better pursue integrative approaches

- to define, which contributions we ask from which research fields, considering that the role and transformative potential of social sciences and humanities is not yet sufficiently acknowledged

- to sharpen our instruments of evaluation not only towards SDGs, but also towards opening them to participation with civil society. How can we best produce and measure economic and technological innovation with SDG criteria? How can we make sure the SDGs are not just a "tick box"? It is not enough to be guided by the classical value chain, we need to develop an added value chain oriented towards the SDGs. Furthermore, we might need to resituate the SDGs along such values for European priorities, such as youth employment, unemployment, poverty and democratic stability and resilience.

Therefore, we need integrative political and institutional approaches: sectoral politics and funding need to be transformed into cross-institutional activities, e.g. better connecting the digital and the research agenda on European level. Sustainable development should be the general layer of all politics. Thus, a substantial monitoring system is a necessary prerequisite for better SDG alignment of European STI policy. 


\subsection{SDG related (research) topics and priorities}

Martinuzzi, in line with several other experts, holds the opinion that the integration of the SDGs must be accomplished across all pillars of the next framework programme, however with different alignments. Martinuzzi explains that "the ERC should focus on RRI and high standards of research integrity instead of trying to assess impacts of ERC funded (fundamental) research. SDG implementation within the ERC could work via the selection of specific experts into the panels. In industry driven research the set of RRI criteria developed by the EU are not suitable and should therefore be aligned with the principles of Corporate Social Responsibility. In this area the SDGs would be highly important as a basis for monitoring outcomes and impacts. Moreover, since industry was involved in the design of the SDGs, it is obvious that they work for socio-economic actors as well. Furthermore, it is wrong to focus all economy related strategies as well as growth and jobs only on the industry pillar. It is a matter of designing a balanced strategy with clear objectives for each of the pillars, with the SDGs as framing vision, however with diverging scopes."

Being part of the writing process of the SDGs, Tjoa is well aware that we urgently need to mainstream the SDGs in science and technology development. Scientists and researchers are not yet fully aware of them and their transformative potential. They have not yet embraced them enough as source for research questions. Tjoa's focus is (i.a.) on how IT can best contribute to the SDGs: "Topics like digitalisation and employment, automation, big data, all of those relate to the SDGs, but are not yet sufficiently translated into research topics or broad research and innovation missions"

Digitalisation and its related technologies and research fields is mentioned by more experts as a core topic that has yet to be examined in the light of the SDGs. "The SDGs and the public discourse of sustainability urgently need to stretch into fields like digitalisation, artificial intelligence, and the discussion of the future but also the limits of humanity and technology. Such debates would enrich policy discourses on how such developments should and could be normatively shaped and regulated.", Messner remarks.

\section{Haberl suggests a concrete empirical research question: "Are we improving well-being by} economic growth? Achieving the SDGS also means consuming less physical, material resources. Societies are organised around economic growth. Therefore, we will have to think about alternative ways to organise societies, and also to measure it. How can we lead a good life within the limits of our planet, less energy, no CO2, no fossil fuels, and so on? How can we organize our societies with less resource consumption?" 
Other topics frequently mentioned are agriculture and energy: Agriculture is as important for energy and climate action, as it is for other SDGs. Until now there has not been enough focus to make agriculture sustainable, Santa-Kahle remarks. Agricultural policies and research policies need to be developed hand in hand, Gerzabek notes. "We can see the sense of urgency increasing, however still not enough political will. Energy and bio-economy should be of highest priority. This needs a clear and definite positioning of policy makers and a lot of preparatory work of stakeholders in national contexts. E.g. in Austria the push for bioeconomy needed 5 years, but now the government program entails the planning of a bioeconomy strategy. Bio-economy as topic offers many opportunities to the development of regions and smart specialization. Via model regions pockets of excellence could be fostered and draw more attention to potential innovators and industry. It could bring more added value to the regions, and even industrial investments."

Migration and security are two other important topics, which yet have to be regarded in the light of the SDGs and the call for systemic change in European socio-economic realities, says Nakicenovic. Correspondingly, several experts remark that the social sciences have been "too integrated", so that they have become invisible. Martinuzzi says: "In H2020 - compared to FP7 - topics are too focused on engineering or natural sciences, driven by technology development. We still have the problem of 'end of the pipe' social sciences, which come in the end for communication, PR or evaluation. We need a deeper and more realistic understanding of the grand societal challenges. As an example, Europe does not seem to have a real issue with mobility or transport, it has the problem of societal disintegration. Europe currently risks falling apart, and it would be of highest priority to fund research on the real grand societal challenges of Europe and its people."

Haberl further states: "We cannot pursue the SDGs and not include the social sciences and the humanities. This will simply not work. The SDGs are also social and cultural goals combined with environmental goals. To tackle them we need highly skilled experts that can conduct interdisciplinary research, which is always messy and complicated. We need people that are ready to get their hands dirty, because we want to induce socio-cultural change, based on what we can find out about patterns of resource use. We need to understand how societies are negotiating such issues and the power games in the background. We need to be persistent." 


\subsection{Other expert recommendations}

The report "The contribution of science in implementing the Sustainable Development Goals" (2016) prepared by members of the German Committee Future Earth gathers recommendations that point to the benefits of close alignment of research and the 2030 Agenda. The following recommendations emphasise possible contributions of internationally coordinated upstream fundamental research to SDG strategies.

\section{The recommended core fields of action are:}

Do encourage interdisciplinary science to increase the knowledge base needed for the most efficient and coherent sustainable development pathways.

\section{To prepare problem- and solution-} oriented synopses in order to better understand, analyse and cope with different types of potential conflicts concerning the SDG implementation process.

(1) To establish platforms for free and open data sharing with transparent metadata that are available to all stakeholders, and can also be used as the basis for creating flexible indicator frameworks.

To foster increased international collaboration and exchange of knowledge and scientific capacity on the global level by intensifying projects such as Future Earth.
D To reinforce the science-policy process by building on good examples such as the UN-SAB IUnited Nation Secretary-General's Scientific Advisory Board) national science advisors and the committees that have been set up to ensure that the best scientific knowledge is available to decision-makers.

\section{(1) To develop more partnerships} between academia, business, civil society and governments in order to find innovative sustainable development solutions through networks such as SDSN

(1) To understand the implementation of the SDGs as a continuous learning process that needs close and regular scientifically based revision

Figure 5 German Committee Future Earth (2016, p12-13)

http://futureearth.org/sites/default/files/2016 report contribution_science sdgs.pdf

The report regards the implementation process of the Agenda 2030 as "continuous learning process that builds on knowledge exchange and close collaboration between different knowledge domains. Strategic foresight can be of invaluable help in addressing the complexity (and time pressures) in the SDG implementation processes. As an independent broker, the scientific community can facilitate discussions between different knowledge 
domains in order to build trust, reduce uncertainties, develop more robust pathways of global sustainable development, and better understand the challenges of implementation (success and failures) and value schemes. However, in order to better evaluate foresighting in the context of SDGs, a deeper understanding is required to pinpoint particular foresight mechanisms and adapt their respective processes to SDGs and the implementation of SDGs. Finally, strong knowledge partnerships where equal weight is given to academics, decisionmakers, practitioners, business leaders, civil society and/or others might be the most efficient way to inform people about SDG implementation on a regional and global level." (p46)

The report prepared by the World in 2050 initiative: "Transformations to Achieve the Sustainable Development Goals" (2018) ${ }^{42}$ provides a very comprehensive reflection on the challenges that come with governing the necessary transformations towards sustainability. In a time when "our nation first" movements dominate the political discourse pursuing the SDGs represents an even more urgent necessity to foster transnational thinking and problem solutions. Its authors present 6 core transformations necessary to achieve the SDGs:

- Substantial advances in human capacity are needed through further improvements of education and health care. Education and health are instrumental for enabling people to live a self-determined life, find decent work and generate income to sustain themselves, but also to undertake climate change mitigation and deal with environmental problems. The ambitions go hand-in-hand with the goals to end poverty in all its forms and to reduce global inequality.

- Responsible consumption and production cut across several of the other transformations, allowing us to do more with less. Evidence shows that it is possible to reduce consumption of resources considerably by taking a more service and circular economy-oriented approach with respect to mobility, housing, food systems, and other sectors of our economies. Reductions in demand leverage large saving potentials at different stages of the supply chain.

- It is possible to decarbonize the energy system while providing clean and affordable energy for all. Pathway analysis shows that energy-efficiency, increasing the share of renewable energy, electrification and carbon-capture and storage all play a key role in decarbonizing the energy system around 2050, while providing access to modern energy for all. Achieving the Paris Agreement is still possible but only if combined with a focus on a broader set of SDGs.

- Achieving access to nutritional food and clean water for all while protecting the biosphere and the oceans requires more efficient and sustainable food systems. It is possible to meet the needs of a growing world population and at the same time limit the food system's environmental impacts by combinations of increasing agricultural productivity, reduction of waste and losses, and changes towards a less meat-intensive diet. The highest priority is to provide healthy and affordable food for all and thereby to eradicate hunger. Heathy diets and lifestyles are also essential for reducing obesity in the world.

- Transforming our cities will ben efit the majority of the world population. Pathways show that by 2050 a round two thirds of human population will live in urban areas. Sustainable cities are characterized by high connectivity and 'smart' infrastructure, enabling high quality services, with low environmental footprint. Transforming slums into decent housing is feasible with low energy and material requirements. Good city design, sustainable lifestyles, empowered local actors and participatory approaches that avoid one-size-fits all solutions are needed to achieve this transformation to sustainable cities.

- Science, tech nology and innovations (STI) are a powerful driver but the direction of change needs to support sustain able development. The digital revolution symbolizes the convergence of many innovative technologies, many of which are currently ambivalent in their contribution to sustainable development, simultaneously supporting and threatening the ability to achieve the SDGs. There is an urgent need to bring the sustainability and the digital and technology communities together to align the direction of change with the 2030 Agenda and a sustainable future beyond. There is also a need to implement forward-looking roadmaps and governance structures that allow the mitigation of potential trade-offs of a STI revolution, particularly relating to its impact on the workplace, on social cohesion, and human dignity.

Figure 6 World in 2050 Initiative: "Transformations to Achieve the Sustainable Development Goals" (2018, p6) http://pure.iiasa.ac.at/id/eprint/15347/

$4^{2}$ World in 2050 Initiative: "Transformations to Achieve the Sustainable Development Goals" 2018 http://pure.iiasa.ac.at/id/eprint/15347/ 
Experts across all reports and also in our interviews call for a robust monitoring systems, that makes SDG related information comparable and better understandable across regions, topics and also most importantly within the SDG system itself.

What is needed is not only a "scoreboard" like the one below, but more a complex mapping of research and innovation portfolios of EU Member States and Associated Countries that is linked to the SDGs. Furthermore, it would be beneficial if the SDGs are also regarded as innovation factor in the EU Innovation Scoreboard ${ }^{43}$.

\begin{tabular}{|c|c|c|}
\hline Country & Region & SDGs \\
\hline Sweden & OECD members & \\
\hline Denmark & OECD members & \\
\hline Finland & OECD members & \\
\hline Germany & OECD members & \\
\hline France & OECD members & \\
\hline Norway & OECD members & \\
\hline Switzerland & OECD members & \\
\hline Slovenia & OECD members & \\
\hline Austria & OECD members & \\
\hline Iceland & OECD members & \\
\hline Netherlands & OECD members & \\
\hline Belgium & OECD members & \\
\hline Czech Republic & OECD members & \\
\hline United Kingdom & OECD members & \\
\hline Japan & OECD members & \\
\hline Estonia & OECD members & \\
\hline
\end{tabular}

Figure 7 Sustainable Development Report Dashboards: Transformations to Achieve the

\footnotetext{
${ }^{43}$ https://ec.europa.eu/growth/industry/innovation/facts-figures/scoreboards en
} 
Sustainable Development Goals https://dashboards.sdgindex.org/\#/ Screenshot retrieved July $29^{\text {th }} 2018$.

The figure above shows the ranking of countries via the SDG Global Index Score developed in the Sustainable Developments Solutions Network. The indicators used hereby compliment other indicator systems as developed by the UN or the EU. However, scoring is not enough to assess the need for RTI in innovation environments and local specificities. It is just the beginning of enhancing effectiveness and handling the trade-offs between competing goals, resource allocation and the planning and foresight of mutually dependent priorities. As the TWI2050 report shows it is urgently needed to develop "science-based transformational and equitable pathways to sustainable development that can provide much needed information and guidance for policy makers responsible for the implementation of the SDGs." At the core of such activities is a "goal based, multi-model quantitative and qualitative integrated analysis that encompasses the full set of SDGs" (p29) and thus a framework that makes the knowledge transfer from local to global and vice versa possible. 


\section{Reactions to the proposal for Horizon Europe}

On 7 June 2018, the European Commission presented its proposal for Horizon Europe, the next framework program for research and innovation (Duration: 2021-2027). MEPs can suggest changes to Horizon Europe before $6^{\text {th }}$ of September. After a compromise phase, where amendments are worked into the text in a 2 months period, a consolidated Parliament position is expected before the end of the year $2018^{44}$.

In this chapter we bring together reactions to the proposal of 3 experts (Ute Stoltenberg, Martin Gerzabek, and A Min Tjoa) and several other statements about Horizon Europe that contained a reference to the SDGs. ${ }^{45}$ Before we present those, we briefly summarize the proposal's main contents.

\subsection{Introduction to the proposal for Horizon Europe}

The Horizon Europe legislative package consists of a proposal for a regulation (including the Rules for Participation) and the Specific Program. The SDGs are prominently mentioned already on page 1, however after a brief general outline of the proposal, we will elaborate how they should be better embedded to the text and the measures planned in order to enfold their potential for a sustainable European STI policy taking in consideration its role also as instrument for cohesion and social well-being.

For this chapter the following documents (all from June 2018 by the European Commission) were analysed in regard to the roles and functionalities ascribed to the SDGs:

\footnotetext{
44 "In the previous legislative cycle, there were around 3,000 amendments for the current research programme, Horizon 2020, and the compromise period lasted seven months. Parliament expects fewer amendments this time because there is little structural change between Horizon 2020 and Horizon Europe. The target is two months for the compromise phase. Eventually, a consolidated Parliament position will emerge and is expected to be voted in the ITRE committee before the end of the year. The schedule is important, officials say, for keeping on track with the Commission's aim of fast-tracking legislation before European elections next May." https://sciencebusiness.net/frameworkprogrammes/news/leading-legislator-horizon-europe-sets-out-his-vision-programme
}

45 Reactions and statements were collected until July 18th with regard to https://sciencebusiness.net/frameworkprogrammes/news/live-blog-reactions-horizon-europe and the news on https://www.era.gv.at/ 
- Proposal on Horizon Europe Regulation

- Proposal on Horizon Europe Regulation Annexes

- Proposal on Horizon Europe Specific Programme Decision

- Proposal on Horizon Europe Specific Programme Decision Annexes

- Horizon Europe Impact Assessment part 1

- Horizon Europe Impact Assessment part 2

Horizon Europe is based on three pillars, somewhat different to Horizon 2020. Whereas in Horizon 2020 pillar 2 and 3 follow quite distinct logics: pillar 2 "Industrial Leadership" supports key technologies, such as microelectronics, advanced manufacturing, etc. across existing and emerging sectors. It also aims at attracting more private investment into R\&I and supporting the increase of innovative SMEs in Europe, and pillar 3 "Societal Challenges" targets research and a much broader concept of innovation for society and citizens (climate, environment, energy, transport, etc.). It supports the development of breakthrough solutions coming from multi-disciplinary collaborations, which include social sciences and humanities. In the proposal for Horizon Europe former pillar 2 and 3 are now folded into one new pillar: Global Challenges and Industrial Competitiveness, which evokes a lot of critique in regard to the pursuit of the SDGs (and other matters), which we will report on below. The new pillar 3 "Open Innovation" is dedicated to the establishment of the European Innovation Council European Innovation Council EIC and will house the European Institute of Technology EIT.

In Horizon Europe the three pillars Open Science, Global Challenges \& Industrial Competitiveness and Open Innovation, are complemented by a fourth program area, "Strengthening the European Research and Innovation Area".

The budget proposed at that time in June 2018 for the period 2021-2027 includes EUR 100 billion (EUR 94.1 billion for Horizon Europe, supplemented by EUR 3.5 billion for the InvestEU fund and EUR 2.4 billion for Euratom).

1) The "Open Science" pillar (EUR 25.8 billion) includes support for pioneering research projects by the European Research Council (ERC, EUR 16.6 billion), scholarships and exchanges for researchers under the Marie-Skłodowska-Curie Program (EUR 6.8 billion) and investments in research infrastructures (EUR 2.4 billion).

2) The Global Challenges \& Industrial Competitiveness pillar ( $€ 52.7$ billion) will support research into societal challenges, technological and industrial capabilities. This pillar will also house the missions (see below) and the Joint Research Center (JRC, EUR 2.2 billion). The thematic priorities in this pillar are summarized in the following clusters:

- Health: $€ 7.7$ billion 
- Inclusive \& Secure Society: € 2.8 billion

- Digital \& Industry: EUR 15 billion

- Climate, Energy \& Mobility: EUR 15 billion

- Food \& Natural Resources: EUR 10 billion

As part of a strategic planning process, Horizon Europe will select and implement missions. According to the Commission proposal, there should not be a separate budget for missions, but instead funds are allocated through the work programs. The Commission estimates that, because of their interdisciplinary nature, missions will receive their budgets from different clusters. It is also planned to implement future FET flagships in Horizon Europe as missions.

3) Under the "Open Innovation" pillar ( $€ 13.5$ billion), the establishment of a European Innovation Council (EIC, $€ 10$ billion) to promote market-building innovation through two instruments (Pathfinder and Accelerator) is planned. In addition, this pillar will also house the European Institute of Innovation and Technology (EIT, EUR 3 billion).

4) The program area "Strengthening the European Research Area" (EUR 2.1 billion) includes, in particular, measures to strengthen scientific excellence (e.g. teaming / twinning, ERA chairs and COST, totalling EUR 1.7 billion) and the Reform of national science systems (e.g. through the Policy Support Facility, totalling EUR 400 million).

\section{Cross-cutting aspects}

Open Science: The principle of "open science" should become the Modus Operandi of Horizon Europe. Beyond the existing open access policy of Horizon 2020, open access to publications and research data (with corresponding opt-out clauses) should be further strengthened ${ }^{46}$.

Partnerships: The Commission proposes to simplify the so far relatively large number of partnership instruments (eg ERA-Nets, JPIs, P2Ps) under Horizon Europe. As a result, there will be three different types of partnerships under the umbrella term "European Partnerships":

- Co-programmed: Collaboration with partners (research stakeholders, companies, foundations) on the basis of a Memorandum of Understanding or a contractual agreement

\footnotetext{
${ }^{46}$ Several reactions to the publication of Horizon Europe remark that it is confusing to call the first pillar Open Science.
} 
- Co-funded: this includes the future EU co-financing, in particular of public research partnerships (based on the previous European Joint Program Cofund instrument in Horizon 2020)

- Institutionalised partnerships: This applies to partnerships based on Art. 185 or Art. 187 (Joint Undertakings, such as the Joint Technology Initiatives) TFEU and the EIT Knowledge and Innovation Communities

Rules for participation: The rules for participation in the core areas provide for a continuity of Horizon 2020. Changes in content include but are not limited to: extended possibilities for the association of third countries (Article 12) and an additional minimum requirement for consortia (Article 18, so far: at least three partners from different Member States or Associated States, new: at least one of these three partners from one Member State). In addition, the rules for participation reflected new or reinforced aspects, such as f.i. the EIC, synergies between different EU programs or "lump sum funding".

Digital Europe: On $6^{\text {th }}$ of June 2018, the European Commission also published its proposals for the InvestEU, the Connecting Europe Facility, EU Space and Digital Europe programs. Digital Europe is a new program that focuses on the application and capacity building in key areas of digital transformation (such as artificial intelligence, supercomputing, cybersecurity, digital skills). According to the plans of the European Commission, Digital Europe will be provided with a total budget of EUR 9.2 billion (2021-2017).

\subsection{The SDGs in the proposal text}

The SDGs are mentioned prominently in the documents and undoubtedly form one of the central reference points for the strategic direction of the program. The involvement of citizens and civil society in defining the research and innovation agenda is also a recurrent theme of the program. However, the text does not owe it to concrete approaches; forms of participation for citizens remain vague and indefinite.

On page 1 at the very beginning of the Proposal on Horizon Europe Specific Programme Decision we read: "The 'Horizon Europe' proposal is fully in line with the Commission's proposal on the next long-term Union budget for 2021 to 2027, as well as the Commission's priorities, as set out in its Agenda for Jobs, Growth, Fairness and Democratic Change and global policy priorities (the Sustainable Development Goals). It supports the agenda of the Union post-2020 as agreed in the Rome Declaration of 25 March 2017." 
Further on, the Sustainable Development Goals are primarily addressed in the 2nd pillar in the 5 focus clusters. Each cluster contributes to several SDGs; and many SDGs are supported by more than one cluster." The interlinking of two separate H2020 pillars under the heading" 47 Global Challenges and Industrial Competitiveness" now brings together competitiveness and sustainable development. How to ensure that the interests of industry and citizens / civil society are equally represented is not apparent from the proposal. It will probably need a concrete "road map" to promote and anchor Horizon Europe's involvement in society before the framework program starts. Furthermore, the turn to the SDGs as well as the commitment to civic engagement require anchoring in institutions and instruments. While there is already a trend towards a new indicator, this institutional anchorage is still completely open.

Now follows a list of excerpts with direct reference to the SDGs from the 4 documents, which illustrate their strategic embedding in the proposal:

\begin{tabular}{|c|c|}
\hline Document & SDG ${ }^{48}$ \\
\hline $\begin{array}{l}\text { Proposal for a DECISION OF THE EUROPEAN PARLIAMENT AND OF THE COUNCIL on } \\
\text { establishing the specific programme implementing Horizon Europe - the Framework } \\
\text { Programme for Research and Innovation (budget-may2018-horizon-europe-decision_en) }{ }^{49}\end{array}$ & 3 \\
\hline $\begin{array}{l}\text { Annex to Proposal for a DECISION OF THE EUROPEAN PARLIAMENT AND OF THE } \\
\text { COUNCIL on establishing the specific programme implementing Horizon Europe - the } \\
\text { Framework Programme for Research and Innovation (budget-may2018-horizon-europe- } \\
\text { decision-annexes_en) }\end{array}$ & 17 \\
\hline $\begin{array}{l}\text { Proposal for a REGULATION OF THE EUROPEAN PARLIAMENT AND OF THE COUNCIL } \\
\text { establishing Horizon Europe - the Framework Programme for Research and Innovation, } \\
\text { laying down its rules for participation and dissemination (budget-may2018-horizon-europe- } \\
\text { regulation_en) }{ }^{50}\end{array}$ & 8 \\
\hline $\begin{array}{l}\text { Annexes to Proposal for a REGULATION OF THE EUROPEAN PARLIAMENT AND OF THE } \\
\text { COUNCIL establishing Horizon Europe - the Framework Programme for Research and } \\
\text { Innovation, laying down its rules for participation and dissemination (budget-may2018- } \\
\text { horizon-europe-regulation-annexes_en) }\end{array}$ & 1 \\
\hline
\end{tabular}

\footnotetext{
47 budget-may2018-horizon-europe-regulation-annexes_en p 2

48 Number of appearances of the term sustainable development goal or SDG

49 https://ec.europa.eu/commission/sites/beta-political/files/budget-may2018-horizon-europe-decision_en.pdf

${ }^{50} \mathrm{https} / /$ ec.europa.eu/commission/sites/beta-political/files/budget-may2018-horizon-europe-regulation_en.pdf
} 

the document Proposals for a REGULATION OF THE EUROPEAN PARLIAMENT AND OF THE COUNCIL establishing Horizon Europe - the Framework Programme for Research and Innovation, laying down its rules for participation and dissemination DECISION OF THE EUROPEAN PARLIAMENT AND OF THE COUNCIL on establishing the specific programme implementing Horizon Europe - the Framework Programme for Research and Innovation COUNCIL REGULATION establishing the Research and Training Programme of the European Atomic Energy Community for the period 2021 - 2025 com plementing Horizon Europe - the Framework Programme for Research and Innovation (swd_2018_307_f1_impact_assesment_en_v6_p2_977548) $)^{51}$

COMMISSION STAFF WORKING DOCUMENT IMPACT ASSESSMENT (Part 1) Accompanying 6 the document Proposals for a REGULATION OF THE EUROPEAN PARLIAMENT AND OF THE COUNCIL establishing Horizon Europe - the Framework Programme for Research and Innovation, laying down its rules for participation and dissemination DECISION OF THE EUROPEAN PARLIAMENT AND OF THE COUNCIL on establishing the specific programme implementing Horizon Europe - the Framework Programme for Research and Innovation COUNCIL REGULATION establishing the Research and Training Programme of the European Atomic Energy Community for the period 2021 - 2025 com plementing Horizon Europe - the Framework Programme for Research and Innovation (swd_2018_307_f1_impact_assesment_en_v7_p1_977548) ${ }^{52}$

The ANNEXES to the Proposal for a DECISION OF THE EUROPEAN PARLIAMENT AND OF THE COUNCIL contain the following references (selection):

- Pillar 1, Research infrastructures: „And the international dimension of EU research infrastructures must be reinforced, fostering stronger cooperation with international counterparts and international participation in European research infrastructures for mutual benefit. Activities will contribute to different Sustainable Development Goals (SDGs) such as: SDG 3 - Good Health and Well-Being for People; SDG 7 - Affordable and Clean Energy; SDG 9 - Industry Innovation and Infrastructure; SDG 13 - Climate Action."

- Pillar 2, general remark: „Greater impact can be obtained through aligning actions with other nations and regions of the world within an unprecedented international cooperation along the lines indicated by the Sustainable Development Goals and the Paris climate agreement. Based on mutual benefit, partners from across the world will be invited to join EU efforts as an integral part of research and innovation for sustainability."

- Pillar 2, "health": „Activities will contribute directly to the following Sustainable Development Goal (SDGs) in particular: SDG 3 - Good Health and Well-Being for People; SDG13 - Climate Action."

\footnotetext{
${ }^{51}$ https://ec.europa.eu/info/sites/info/files/swd_2018_307_f1_impact_assesment_en_v6_p2_977548.pdf

${ }^{52}$ https://ec.europa.eu/info/sites/info/files/swd_2018_307_f1_impact_assesment_en_v7_p1_977548.pdf
} 
- Pillar 2, „inclusive and secure societies": „Activities will contribute directly to the following Sustainable Development Goals (SDGs) in particular: SDG 1 - No Poverty; SDG 4 - Quality Education; SDG8 - Decent Work and Economic Growth; SDG 9 - Industry, Innovation and Infrastructure; SDG 10 - Reducing Inequalities; SDG 11- Sustainable Cities and Communities; SDG 16 - Peace, Justice and Strong Institutions."

- Pillar 2, "digital and industry": „Activities will contribute directly to the following Sustainable Development Goals (SDGs) in particular: SDG 8 - Decent Work and Economic Growth; SDG 9 - Industry, Innovation and Infrastructure; SDG 12 - Responsible Consumption and Production; SDG-13 Climate Action."

- Pillar 2, "climate, energy and mobility": „Activities will contribute directly to the following Sustainable Development Goals (SDGs) in particular: SDG 7 - Affordable and Clean Energy; SDG 9 - Industry, Innovation and Infrastructure; SDG 11 - Sustainable Cities and Communities; SDG 13 - Climate Action.... Decarbonisation pathways, mitigation actions and policies covering all sectors of the economy, compatible with the Paris Agreement and the United Nations Sustainable Development Goals;"

- Pillar 2, „food and natural resources": „Research and innovation activities under this Cluster contribute in particular to the implementation of the goals of: the Environmental Action Programme, the Common Agricultural Policy, the Common Fisheries policy, the Food Law legislation, the Maritime policy, the Circular Economy Action Plan, the EU Bioeconomy Strategy, and the 2030 climate and energy framework as well as EU legal provisions to reduce air pollution. Activities will contribute directly to the following Sustainable Development Goals (SDGs) in particular: SDG 2 - Zero Hunger; SD 6 - Clean Water and Sanitation; SDG 11 - Sustainable Cities and Communities; SDG 12 Responsible Consumption and Production; SDG 13 - Climate Action; SDG 14 - Life Below Water; SDG 15 - Life on Land."

- Part 4, „strengthening the European Research Area": „The activities supported under this part addresses ERA policy priorities, while generally underpinning all parts of Horizon Europe. Activities may also be established to foster brain circulation across ERA through mobility of researchers and innovators. The goal is for an EU where knowledge and a highly skilled workforce circulate freely, research outputs are shared rapidly and efficiently, researchers benefit from attractive careers and gender equality is ensured, where Member States develop common strategic research agendas, aligning national plans, defining and implementing joint programmes, and where the outcomes of research and innovation are understood and trusted by informed citizens and benefit society as a whole. This part will contribute de facto to all Sustainable Development Goals (SDGs), but directly to the following: SDG 4 - Quality Education; SDG 5 - Gender Equality; SDG 9 Industry, Innovation and Infrastructure; SDG 17 - Partnership for the Goals." 
In the Proposal for a REGULATION OF THE EUROPEAN PARLIAMENT AND OF THE COUNCIL establishing Horizon Europe - the Framework Programme for Research and Innovation, laying down its rules for participation and dissemination the SDGs are also prominently mentioned already on page 1 .

Already in the first paragraph describing reasons and objectives it is stated "The 'Horizon Europe' proposal is fully in line with the Commission's proposal on the next long-term Union budget for 2021 to 2027 as well as the Commission's priorities as set out in its Agenda for Jobs, Growth, Fairness and Democratic Change and global policy priorities (the Sustainable Development Goals). It supports the agenda of the Union post-2020 as agreed in the Rome Declaration of 25 March 2017." (p1)

"The conception and design of the Programme should respond to the need for establishing a critical mass of supported activities, throughout the EU Union and through international cooperation, in line with the UN Sustainable Development Goals (SDGs). Programme implementation should reinforce the pursuit of this aim." (p17)

"The pillar 'Global Challenges and Industrial Competitiveness' should be established through clusters of research and innovation activities, in order to maximise integration across the respective work areas while securing high and sustainable levels of impact in relation to the resources that are expended. It will encourage cross-disciplinary, cross-sectoral, cross-policy and cross-border collaboration in pursuit of the UN SDGs and the competitiveness of the Union's industries therein." (p17)

International cooperation is situated in close relation to the SDGs: "The Programme should promote and integrate cooperation with third countries and international organisations and initiatives based on common interest, mutual benefit and global commitments to implement the UN SDGs. International cooperation should aim to strengthen the Union's research and innovation excellence, attractiveness and economic and industrial competitiveness, to tackle global challenges, as embodied in the UN SDGs, and to support the Union's external policies." (p20)

And finally Article 3 of the general provisions lists as number 1 programme objective: "The Programme's general objective is to deliver scientific, economic and societal impact from the Union's investments in research and innovation so as to strengthen the scientific and technological bases of the Union and foster its competitiveness, including in its industry, deliver on the Union strategic priorities, and contribute to tackling global challenges, including the Sustainable Development Goals." (p28) 
The working document on IMPACT ASSESSMENT includes several references to the SDGs.

In the Commission Staff working document "IMPACT ASSESSMENT. Accompanying the document Proposals for a REGULATION OF THE EUROPEAN PARLIAMENT AND OF THE COUNCIL establishing Horizon Europe - the Framework Programme for Research and Innovation, laying down its rules for participation and dissemination, DECISION OF THE EUROPEAN PARLIAMENT AND OF THE COUNCIL on establishing the specific programme implementing Horizon Europe - the Framework Programme for Research and Innovation, COUNCIL REGULATION establishing the Research and Training Programme of the European Atomic Energy Community for the period 2021-2025 complementing Horizon Europe - the Framework Programme for Research and Innovation" hosts several mentions of the SDGs, as will be outlined below.

Already the second paragraph of the executive summary states: "Research and innovation help Europe deliver on citizens' priorities, as embodied in the Sustainable Development Goals and in the Paris Agreement on fighting climate change, to bring about sustainable growth and high-quality jobs, and to solve present and unforeseen global challenges. However, Europe overall currently underinvests in research and innovation compared to its main trading partners, and so risks being irreversibly outpaced." (p3)

"Two paragraphs later: "Horizon Europe's general objectives stem from the Treaty on the Functioning of the European Union. These will be: to strengthen the scientific and technological bases of the Union and foster its competitiveness, including for its industry; to deliver on the EU's strategic policy priorities and contribute to tackling global challenges, including the Sustainable Development Goals. To address particular research and innovation challenges faced by the EU, Horizon Europe also has specific objectives. All objectives apply across the Programme, and all individual Programme parts will contribute to their achievement." (p3) 
In particular part 2, Annex 6 on Indicators of the document gives a bit more details on how the SDGs are integrated in the framing of impact and planned assessment methods:

\subsection{Societal impact pathway indicators}

The Programme is expected to have societal impact by addressing EU policy priorities through R\&I, delivering benefits and impact through R\&I missions, and strengthening the uptake of research and innovation in society. Progress towards this impact will be monitored through the proxy indicators in Figure 13, set along three key impact pathways.

Figure 13 Key societal impact pathways \& progress indicators

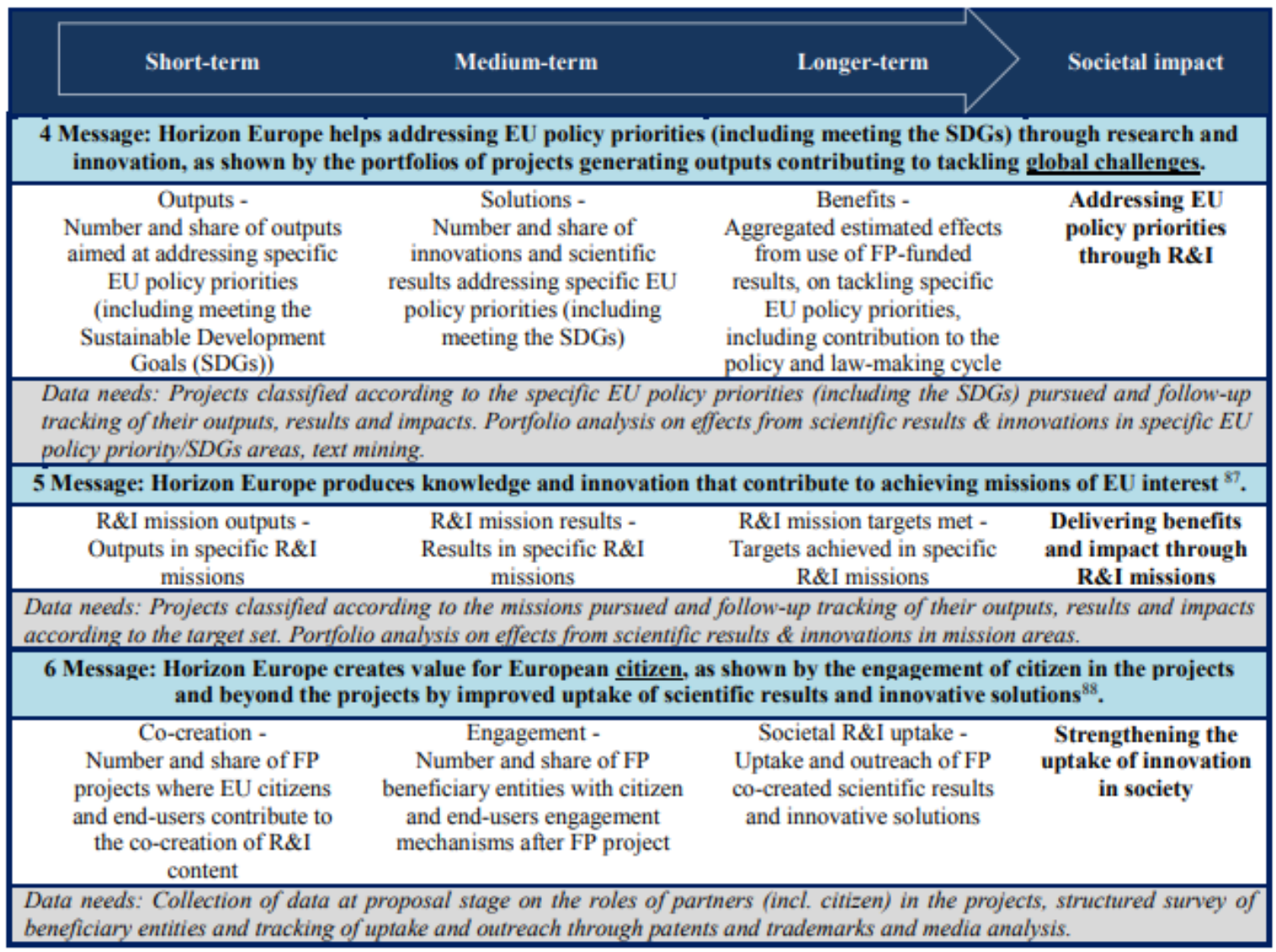

Figure 8 Societal impact pathway indicators.Screenshot from the document accompanying the Horizon Europe proposal IMPACT ASSESSMENT,p47. 
In Chapter 11 of Annex 7 we learn about potential synergies with other proposals under the future MFF: R\&I activities in the Erasmus programme should "foster the emergence of multidisciplinary and multilingual environments where students, lecturers, researchers and other public and private actors co-create and co-share knowledge and innovation, working together to address global societal challenges (for example: they could focus on SDGs or priorities of the Framework Programme)." (p67)

International competitiveness of European higher education institutions will be progressively increased by "fostering opportunities for students, teachers, researchers and other public and private actors to co-create knowledge and innovation together (e.g. working together to address global societal challenges, Sustainable Development Goals or priorities identified by the Framework Programme). (p68)

In chapter 12 on the synergies with the Neighbourhood, Development and International Cooperation Instruments, the SDGs are regarded as domain in the R\&I related support (p68).

In Annex 8 "Detailed information on key improvements in the design of Horizon Europe" chapter 2 on Research and Innovation missions includes a quote from as stakeholder position: "Continuing the explicit alignment of the United Nations Sustainable Development Goals with the future Framework Programme's missions is warranted for Europe to become the global leader in research and innovation. Europe and its trading partners need a Framework Programme that is mission-oriented, addresses both current and future global challenges, and encourages bottom-up solutions" and the Mazzucato report is also quoted for its focus on the SDGs (p90-92). Furthermore, the SDGs are reflected in the conceptualisation of international cooperation ( $\mathrm{p} 100$ ) and within the institutionalisation of policy support, such as in the Joint Research Centres (p122).

\section{Where are the SDGs not mentioned at all?}

The SDGs are not mentioned in Pillar 1 in reference to the ERC and the MSCA. Furthermore, they are not mentioned in Pillar 3, which is surprising given the fact that the EIT already plans strategically with the SDGs. 53

\footnotetext{
53 https://eit.europa.eu/sites/default/files/eit_strategic outline 0.pdf
} 


\subsection{Reactions to the proposal for Horizon Europe in respect to the roles and functions of the SDGs}

After the publication of the proposal for Horizon Europe three experts shared their comments with us, which will be elaborated in detail below. A superficial scanning of position statements following the publication of the proposal until mid-July 2018 produced only sparse reactions in respect to the roles and functions of the SDGs in the proposal text. We will summarize them following the expert statements below. Missed opportunities or missing links will be highlighted.

\section{The framing of the SDGs}

"The SDGs are mentioned in the proposal text, but they are not really integrated, " notes Ute Stoltenberg. „There are so many potentials not considered at all. While reading you get the impression that the SDGs are treated like an ,add on', in the sense of: , we also take in the SDGs'. This is a wrong approach. You cannot work the SDGs like tasks. On the contrary, they must be constantly negotiated, they must be experimented with".

\section{Martin Gerzabek says: "A research framework program based on the SDGs would need a} completely different structure. Overall, I judge the objective of including the SDGs to be quite serious. We see the attempt of trying to establish relationships between the work program and SDGs (for example, within the framework of the Grand Challenges). However, it is obvious that the SDGs were not used as blueprint or concrete planning instrument." He doubts that pillar 2 will achieve the necessary cross-linking between the thematic clusters. Even though the challenges addressed in the proposal text are equipped with the respective SDGS, this is not enough. They need to be linked and studied across each other: "This would be absolutely necessary for the implementation of the SDGs, since these are of intrinsically networked nature and cannot be considered individually."

Especially in regard to pillar 2 the European University Association remarks: "The pillar on global challenges and industrial competitiveness needs a broad definition of its objectives in attaining the Sustainable Development Goals spanning across sector and all areas of innovation. It should not be narrowed down to contributing towards industrial competitiveness, but rather strive in addition for a wide range of societal benefits." 54 Germany calls "for the individual goals of the SDGs to be taken as guidance for setting the topics and formulating the calls for proposals in the Clusters." 55 Similarly, in its statement the

54 https://sciencebusiness.net/sites/default/files/inline-files/Horizon\%20Europe\%20-

$\%$ 20University\%20Associations\%20Proposed\%20Amendments.pdf

55 https://www.era.gv.at/object/document/4224/attach/Deutschland.pdf 
European platform for Civil Society Organisations urges Member States and the European Parliament to secure an independent pillar for global challenges, "whose objectives and priority setting focus solely on addressing societal challenges, guided by the Sustainable Development Goals (SDGs) and the Paris Climate Agreement, acknowledging that excellent R\&I in this area will create quality jobs and has a significant economic return, in and of itself, and without adding 'industrial competitiveness' to the programme pillar"56.

Gerzabek notes that even though the SDGs are missing or mentioned there only roughly, both pillar 1 Open Science and pillar 3 Open Innovation "could bring a substantial advantage for the SDGs, since here the interdisciplinarity and above all also the transdisciplinarity is promoted. In open innovation, however, the SDGs are not mentioned at all." He further comments: "The ERC could also contribute significantly to the achievement of the SDGs. Here one is obviously subject to the fallacy that basic research does little to solve the big problems."

Stoltenberg adds: "If there is talk of pioneering research in the Open Science pillar, then the SDGs have to be mentioned there. Because the SDGs are not always about immediate implementation. That is a misunderstanding of the Commission proposal. Because here it is assumed that an orientation to the SDGs can only lie in the direct feasibility. That is a wrong understanding of sustainability." She remarks that in the 3rd pillar, the SDGs are completely missing. "This is really a missed opportunity. 'Market opportunities' and 'innovation' are terms that urgently should be filled with meaning. This is particularly relevant with regard to the topic of digitization. These are processes that must be shaped and oriented towards the 2030 Agenda. Pillar 3 is supposed to deal with 'rapid market growth' immediately. The subordinate clause is missing: 'in the sense of sustainable development'."

\section{Evaluation, monitoring and foresight}

After his reading of the proposal for Horizon Europe A Min Tjoa is even more convinced that the SDGs have to be made obligatory and be embedded in all research projects via both the grant contract and the evaluation procedure. It would also be important to create better coordination for monitoring and foresight, which is not yet included into the proposal text at all.

Stoltenberg notes that SDG relevant evaluation criteria seem to be missing from Annex V: "In the listed criteria under which submissions are to be reviewed the SDGs are missing. Furthermore, the given criteria will hardly help with social transformation. In this regard it is

${ }^{6}$ http://www.ghadvocates.eu/wp-content/uploads/civil-society-reaction-to-FP9-proposal2.pdf 
also important to talk about the involvement of civil society in the evaluation and assessment processes. That would increase the credibility of such a program."

SDG relevant monitoring is also requested by a European platform of Civil Society Organisations: "To ensure public return on investment and accountability, all future pillars and programme parts of Horizon Europe-including European Partnerships -need to include adequate safeguards, that mainstream sustainable development". Project proposals should be assessed "based primarily on their potential to deliver on societal challenges; and measures performance based on adequate societal impact indicators that focus on the progress towards the realisation of the SDGs" 57 .

The Netherlands Federation of University Medical Centres notes that the introduction of Sustainable Development Goals as key impact parameters "should involve the entire value chain starting from the very basis of all innovations, i.e. fundamental research. Moreover, the European science base, researchers and industry need access to state of the art research and innovation (R\&l) infrastructure, with interdisciplinary interlinkages between local, national, European and global (data) infrastructures". ${ }^{8}$

This call for better monitoring and inclusion of SDG relevant indicators into the design of evaluation is also underlined in the statements of the European Public Health Alliance ${ }^{59}$ : "Measuring the social impact of public funding for R\&I by developing SMART indicators which will assess the impact of R\&I funding in FP9 on health-related Sustainable Development Goals." And of the European University Association ${ }^{60}$ : "Page 16, Annex V, societal impact pathway indicators table, 3rd row, 1st column short term: Add the Sustainable Development Goals Number and share of outputs aimed at addressing specific EU policy priorities and the Sustainable Development Goals. One of the objectives of Horizon Europe is to contribute to the Sustainable Development Goals. The SDGs go beyond the EU's changing policy priorities, and therefore their inclusion in the indicators brings long-term perspective to the societal impact of the programme."

\footnotetext{
57 http://www.ghadvocates.eu/wp-content/uploads/civil-society-reaction-to-FP9-proposal2.pdf

${ }^{8} \mathrm{https}$ ://www.neth-er.eu/en/news/Netherlands-Federation-University-Medical-Centers-reaction-Horizon-Europe 59 https://epha.org/open-letter-in-reaction-to-council-conclusions-from-the-interim-evaluation-of-horizon-2020towards-the-9th-framework-programmel

${ }^{60}$ https://sciencebusiness.net/sites/default/files/inline-files/Horizon\%20Europe\%20-

\%20University\%20Associations\%20Proposed\%20Amendments.pdf
} 


\section{Citizen engagement and multi-stakeholder approaches}

Experts agree, if Europe is meant to provide stronger support than previous framework programmes for the political agenda of the European Union, more societal involvement is key. With respect to the involvement of civil society in all kinds of processes in line with the SDGs, as called for in several instances of the proposal text, there are several reactions pointing to the necessity of more elaborated definitions of types of citizen involvement, e.g. whether it is envisioned to improve knowledge transfer, science communication or increase participation in decision making. Moreover, since only vague commitments on engaging society are not enough - especially not in the context of a pillar that is also dedicated to industrial competitiveness - it will be necessary to set out a concrete roadmap to boost societal engagement before the beginning of the programme ${ }^{61}$.

The second pillar should be "co-programmed with citizens and civil society, acknowledging them as key stakeholders in identifying and addressing societal challenges and ensuring a needs-based R\&I priority setting. In particular, a roadmap is urgently needed on how Horizon Europe will overcome barriers to CSO and citizens engagement" ${ }^{\prime 2}$.

In a first reaction ${ }^{63}$ with several suggestions for amendments in the proposal text ECSITE the European Network of Science Centres and Museums - remarks: "The engagement of citizens should not be confused with public outreach. Engagement refers to actions aimed, notably, at mutual learning between different types of stakeholders and does not refer to one-way transmission from experts to publics. [...] Engagement can include public outreach but is not limited to it. [...] Rather than aiming at generating support for the Programme, the engagement of citizens and civil society should aim at developing multi-stakeholder approaches essential to reach the SDGs. The Programme should support citizens' needs, not the other way around. It should offer a better balance between market return and public return. Social sciences and humanities need to be much more strongly associated to the R\&l system: fake news, changes in citizens' behaviours to address climate change, concerns related to the profound transformations that technologies will bring, are some of the many worrying phenomena that can only be addressed by closely working with $\mathrm{SSH} . "$

\footnotetext{
${ }^{61}$ https://www.euractiv.com/section/economy-jobs/opinion/citizens-and-sustainable-development-are-big-losers-ineus-next-research-programmel

${ }^{62}$ http://www.ghadvocates.eu/wp-content/uploads/civil-society-reaction-to-FP9-proposal2.pdf

$6_{3}$ https://www.ecsite.eu/sites/default/files/ecsite_he_amendments_regulation-decision_annexes.pdf
} 


\section{Social Sciences and Humanities}

The last statement already points to the unease of many stakeholders with the absence of social sciences and humanities, especially in regard to the SDG relevant themes in the proposal. Stoltenberg remarks that the social sciences and humanities are vital not only for the pursuit of the SDGs but also for understanding their interconnectedness better. Technological innovations are always socio-technological. Furthermore, the proposal lacks acknowledging the importance of "risk-estimating research that assesses the broad impact of research and innovation on the SDG goals". Tjoa restates his opinion that "there is no SDG compatible collaborative research that does not include the SSH." Stoltenberg notes: "Linking regional, national and global perspectives always requires a social and humanistic perspective." Grand challenges are global by nature and if aligned with the SDGs co-producing knowledge and finding solutions requires a strong contribution from $\mathrm{SSH}$, which need to be included in genuinely interdisciplinary projects in the second pillar. In the statements of Germany and several other stakeholders it is called for a distinction of social sciences, humanities and security research, as they are "hardly compatible in terms of their target audiences, research goals and funding mechanisms. With regard also to dual-use relevance, the independence of the two fields should be retained in separate Clusters as in Horizon 2020"64.

\section{Missions}

Stoltenberg asks whether the concept of the missions is encompassing the search-, education-, learning- and design process, that the SDGs would require in such a setting. Moreover, she calls for the equal inclusion of all stakeholders in the design, implementation and assessment of missions: "The formulation of missions in cooperation with civil society is in principle very welcome. But everyone has to sit at a table. And there are some contradictions in the Commission's proposal, so real openness is often pervaded by very clear directions, measurability and time constraints. Precise goals should be formulated, but that's not how it works." Another important aspect concerns the capacities of stakeholders to take part in those processes. Stoltenberg remarks: „you cannot make civil society "fit" to contribute, and the instruments should be made fit for civil society."

\section{Interdisciplinarity}

There should be better incentives for interdisciplinary projects that strongly relate to the SDGs, such as boni or specific instruments, says Tjoa. Very similar to the comments before

\footnotetext{
${ }^{64}$ https://www.bmbf.de/files/Position_Paper_Horizon_Europe_Web.pdf
} 
the publication of the EC proposal experts agree on the importance of increased interdisciplinarity and adequate structures for the implementation and assessment of interdisciplinarity especially for pillar 2 'Global Challenges and Industrial Competitiveness', which should not only strengthen collaborative frontier-led research to "bring together Europe's best minds and address the UN Sustainable Development Goals" (The Guild statement), but also to foster collaboration across disciplines. The European universities are pleased that "Pillar 2 will aim at tackling global challenges articulated in the Sustainable Development Goals. The Association calls, however, for innovative ways of approaching these challenges by ensuring interdisciplinarity and cross-sectoral collaboration. They are highly interconnected and thus cannot be solved by a single discipline. Addressing global challenges through achievable missions programmed within Pillar 2 will help Europe deliver on strategic policy priorities. It will also foster widespread support for core European values such as equity and solidarity." ${ }^{65}$

\section{Education and SDGs}

Tjoa misses a link to education and educational research, which is fundamental for the SDGs and is itself an SDG (SDG 4). In the Europe 2020 strategy education is part of 5 ambitious objectives, each with specific European and national targets. It is thus necessary to build on this and widen the perspective to the SDG relevant targets. This missing dimension is also underlined by Stoltenberg. She says: "The second pillar mentions some of the SDGs in the clusters, and there is some talk of "skills," but education itself is not mentioned. This is questionable because sustainable development is a learning process, so education should always be added as a research moment. In each cluster, education should be explicitly named. Without a proper organization of education, sustainable development cannot happen." Furthermore, education aspects should be considered necessary for every SDG relevant research policy (also on national level): it is not only about future skills of researchers, it is about future skills of society at large, the skills for societal change towards to SDGs and more citizen engagement in research related activities. In its statement Germany advocates that Education Research be firmly established as an Area of Intervention.

\section{Innovation}

In the proposal the European Commission merges former second and third pillars of Horizon 2020 into a new pillar under the heading "Global Challenges and Industrial Competitiveness". Experts raise concerns that thus an economic logic will dominate all research and will put the pursuit of the SDGs at risk (as well as other important objectives and desired impacts).

${ }^{6}$ http://www.eua.be/Libraries/publications-homepage-list/horizon-europe-eva-analysis-of-the-european-commissionproposal 
Profit and competitiveness are not the right logics to operationalise grand societal challenges. From the proposal it remains unclear how the programme will achieve alignment between these very distinct agendas and how they are compatible with the SDGs.

Furthermore, the term innovation is not used in a broad enough manner.

TP Organics - one of 40 European Technology Platforms (ETP) - is concerned that the second pillar will "prioritise industrial competitiveness over societal challenges and sustainable development. [...] The proposal for Horizon Europe suggests merging 'industrial competitiveness' and 'global challenges' in the same pillar. Blurring both objectives risks limiting the already-scarce funding available for addressing societal challenges, and importantly may exclude research approaches that deliver public goods rather than private benefits. We call for a specific pillar for research and innovation that will help Europe to reach the objectives of the UN Sustainable Development Goals and the Paris Climate Agreement" ${ }^{\prime 66}$.

There are several demands that "public investments must generate public returns", as the Civil Society Organisations' platform puts it. Therefore, the key question will be how to balance a focus between "scientific excellence, economic and societal impact. Industry is a key partner also in delivering societal impact, but merging and blurring profit-oriented objectives with societal impact-oriented objectives risks limiting the already-scarce funding available for addressing societal challenges, endangers a needs-based R\&I agenda, threatens the traceability of public funding needed to monitor public return on public investments and risks further excluding citizens and civil society from R\&I." ${ }^{67}$

In pillar 3 the SDGs are missing from the text, which seems to be a missed opportunity, experts agree, as the SDGs could provide a blueprint for assessment criteria and a rich resource for the design of specific agendas. Stoltenberg notes: "Industrial leadership must have a sense of social and environmental responsibility". The proposal does not reflect this aspect enough; furthermore it does not frame the SDGs as business opportunity ${ }^{68}$.

"Industry should anticipate future environmental regulations and better prepare for it. This is an important aspect of competitiveness; therefore, the SDGs provide a good blueprint for foresight in that regard", says Tjoa. In this respect, industry associations, like the European Chemical Industry Council, already emphasise their commitment to the SDGs in regard to the proposal for Horizon Europe: "The European Chemical Industry invests more than $€ 9$ billion in

\footnotetext{
${ }^{66}$ http://tporganics.eu/tp-organics-press-release-on-horizon-europe/

${ }_{67}$ http://www.ghadvocates.eu/wp-content/uploads/civil-society-reaction-to-FP9-proposal2.pdf

${ }^{68}$ For more information on that see the PWC study:

https://www.pwc.com/gx/en/sustainability/SDG/SDG\%20Research_FINAL.pdf and the EC presentation the SDGs in EU policy https://www.ukro.ac.uk/aboutukro/Documents/180622_ukro_conference_bordignon.pdf
} 
research and innovation every year to develop technologies essential to achieving a low carbon and circular economy as well as meeting the United Nations Sustainable Development Goals. Continuous innovation funding is key to support the chemical industry in developing necessary technologies and subsequently in investing in Europe." ${ }^{69}$

The SDGs are already part of industrial leadership: Tjoa reports that several industry leaders have already understood this very well: "Today, a French leading energy provider is able to sell green energy for a very low price (0,02-0,03 EUR/kilowatt hour), but remains still profitable by working with a highly localised energy grid. Exporting this concept to other countries is highly successful and opens new opportunities for local energy production, however, this has to be systematically investigated, and set into an experimental frame." The missions would be a good setting for this, given they are a multi-stakeholder driven process. Such research could also unlock more local potential and help widening strategies for European STI.

\section{Widening participation and strengthening the European Research Area}

Experts see another missed opportunity in the only partial role of the SDGs in part 4 of the proposal. Even though the proposal states that "this part will contribute de facto to all Sustainable Development Goals (SDGs), but directly to the following: SDG 4 - Quality Education; SDG 5 - Gender Equality; SDG 9 - Industry, Innovation and Infrastructure; SDG 17 Partnership for the Goals", it does not fully exploit the potential of the SDGs themselves as themes or strategies of cooperation.

Stoltenberg remarks "On page 3 of the proposal there is an interesting sentence: 'The European citizens are to be supported in these turbulent times'. First of all, it would be better if the European citizens were to be involved in the design of STI in order not to be afraid of the turbulent developments, but to work together to come up with solutions. Second, this would build important bridges to actors at the country level. The issue of social cohesion in Europe and the foundations for democratic and good coexistence requires responding to regional knowledge and involving regional actors." There are several institutions and actors, that should be involved in building the bridges across Europe via SDG linked activities (e.g. European Technology Platforms), but also instruments and strategies, such as ERA and the European Higher Education Area (EHEA). This would not only help to foster education and future skills, improve human capital, it would also empower universities and increase access to civil society and local knowledge and expertise.

In line with Nakicenovic (see Chapter 5), Stoltenberg adds: "Participation always means, first of all, that new knowledge for solving problems is acquired. We have to look deeper, we

\footnotetext{
${ }^{69}$ http://www.cefic.org/newsroom/News/Cefic-Horizon-Europe-proposal-reflects-the-true-value-of-Europe/
} 
need more detailed knowledge to link regional, national and global perspectives." By learning from experiences with specific instruments dedicated to widening activities (e.g. ERA chairs, Teaming or Twinning Actions, ...) the programme should align them better with the SDGs and foster knowledge exchange and infrastructure collaboration in regard to the untapped potentials of bringing together regional and global knowledge. Turning environmental problems into solutions and furthermore into business opportunities e.g. by creating low carbon circular economies will require systematic exchange and a strategy spanning over all instruments ${ }^{70}$. Therefore, reporting and monitoring on the SDGs, as well as the setup of a high-level stakeholder platform for European SDG related objectives should be planned with regard to knowledge exchange and mobility in STI area, European regional development and national ERA roadmaps.

\footnotetext{
$7^{\circ}$ See also "Changing gear in R\&I: green growth for jobs and prosperity in the EU" - Report of the European Commission Expert Group
} 


\section{Conclusions}

This report's focus is four-fold: We bring together 1) positions of EU high level experts, working groups and research documents, 2) stakeholder and country position papers and 3) commentaries of experts before and after the publication of the proposal for Horizon Europe on June $7^{\text {th }}$ 2018. The objective is to create a highly differentiated and multi-perspectival analysis of the potential and implementation of SDGs in European STI policy. Such a multiperspectival analysis is necessary for navigating the broad range of positions and staying attentive towards potential challenges and trade-offs.

We ask: How are the SDGs appearing in commissioned or referenced policy papers and in the position papers of stakeholders? Do the position statements address the SDGs as potential frame for thematic, processual or organisational planning? How are they mentioned as source for monitoring progress and controlling compliance to European visions? How are the SDGs appearing in the proposal for Horizon Europe?

We find consensus in most of the input documents and expert statements, be it from policy reports or stakeholder position statement, as well as from interviews experts that the term innovation has to be broadened to encompass also non-technological and non-economic aspects, such as social well-being and security, stability, environmental action, and political improvements. This is an important prerequisite to the discussion of the implementation of the SDGs within STI policies.

Besides the fact that all analysed expert or high-level policy reports and the experts in our interviews unanimously agreed to the importance of the SDGs for the next STI framework programme and their potential as multilateral social contract, the SDGs are only partially represented in the bulk of stakeholder statements. As the chapters of this report have demonstrated, the majority of positions refer to the SDGs as thematic resource and grand framing of the next framework programme. Only marginally are the SDGs brought in relation with specific types of monitoring or indicators, which is probably due to the level of a general perspective instead of in-depth elaboration. In interviews with experts we also raised these questions, bringing about several important recommendations how the SDGs can be made productive on processual and organisational level and more general calls for action. These points guided the analysis of the proposal for Horizon Europe, which was published on June $7^{\text {th }} 2018$. 
Experts call for the emancipation of the SDGs from the "green policy" niche. They point to the necessity (and urgency) of reflecting technological developments such as digitalisation, automation, or artificial intelligence, but also societal challenges like security and migration in the light of the SDGs. Experts draw attention to the opportunities and potentials of HEls in SDG related innovation, also with a strong focus of their potential for participatory approaches and stakeholder involvement.

In regard to the roles and functions of the SDGs the proposal of Horizon Europe is criticized for not using them as blueprint across all pillars, especially in pillar 3, despite the fact that even the EIT itself plans its strategies in line with the SDGs ${ }^{71}$. It is feared that with the merging of societal challenges and industrial competitiveness into one pillar, the economic logic and profit orientation will dominate any other objective. This might hinder knowledge transfer, citizen participation in the sense of co-creation of research agendas and coevaluation of impact, as well as the pursuit of the SDGs in general.

Monitoring and evaluation of STI in regard to the SDGs should be expanded as it could provide a good basis for robust science-society-policy interfaces, if implemented from the beginning and structurally integrated in respective instruments and institutions (also and especially those related to innovation). Knowledge transfer within and between European and national bodies has to be enhanced. There need to be established better hubs for strategic intelligence and communication, as well as contact points in order to ensure policy coherence and provide the knowledge base for agenda setting and resource allocation. Moreover, if the SDGs should become a business opportunity and competitive advantage, knowledge has to be made available to all relevant stakeholders.

Research and innovation policy and funding related institutions should initiate capacity building for more participatory approaches and the evaluation of socio-economic, environmental and policy impact of STI. This will be of highest priority when establishing mission-oriented strategies. Experts call for European leadership in sustainable development also in terms of developing the right monitoring and evaluation systems.

However, experts warn that right now there is too much parallelism; sustainable development has to be mainstreamed in every aspect and in all pillars in order to become operational (based on efficient monitoring and knowledge transfer). Hereby, it has to be considered that SDGs are mutually dependent and cannot be treated like "tasks"; on the contrary they should function as frames for more experimentation and education.

\footnotetext{
${ }^{71}$ https://eit.europa.eu/sites/default/files/eit_strategic_outline_0.pdf
} 
Experts would like to see the SDGs more prominently in area 4 of Horizon Europe, carefully designing the actions for widening participation and strengthening ERA along the SDGs, as they could bring opportunities in terms of research mobility, knowledge transfer but also industrial competitiveness of lower performing countries and broader social innovation.

Furthermore, experts call for more pressure of member states, regions and cities, as well as more push on the part of the European Parliament for the implementation of the SDGs into STI policies. Such pressure would also help to resituate the framing of the SDGs as environmental add-on to becoming a competitive advantage and important key element of European Added Value. Therefore, many pressing issues should be addressed, including the following:

- SDG Compliance: It is necessary to investigate how turning SDG compliance into an asset might benefit transformation and commercialisation for EU research and innovation actors and in general, future and emerging breakthrough innovations.

- Broadening advocacy and making it more effective: How can bringing together industry leaders actively promoting the SDGs (e.g. from global innovation leading and deep-tech companies in the life science sector) and advocacy from civil society and policy making help to build coherent and adaptable funding streams and instruments to both benefit and enrich the mission-oriented approach and finding the right paths to advanced research.

- Designing efficient instruments: What kind of instruments are needed to pursue the direction from mission to market, building on experiences with for example the FETs, KIC (EIT) and others.

- Fostering participation in innovation related contexts: How could building on public engagement and participation and creating a knowledge base on co-creation based on SDG compliance strengthen the role of the EIC and EIT.

- SDGs as Added Value: How can the SDGs stimulate innovation ecosystems and crossnational as well as international cooperation creating EU added value. 


\section{References}

Colglazier, E. W. (2018). The Sustainable Development Goals: Roadmaps to Progress. Science \& Diplomacy, 7(1). Retrieved from http://www.sciencediplomacy.org/ editorial/2018/sdgroadmaps

Commission Staff Working Document - Executive Summary of the Interim Evaluation of Horizon 2020. (2017). Retrieved from https://ec.europa.eu/research/evaluations/pdf/20171009_a185_swd.pdf

Directorate-General for Research and Innovation (European Commission). (2015). The role of science, technology and innovation policies to foster the implementation of the sustainable development goals (SDGs) Report of the expert group 'Follow-up to Rio+20, notably the SDGs' Study.

Directorate-General for Research and Innovation (European Commission). (2018). Towards a mission-oriented research and innovation policy in the European Union. An ESIR memorandum Study. Retrieved from https://publications.europa.eu/en/publication-detail//publication/4177ae56-2284-11e8-ac73-01aa75ed71a1

EU SDG indicator set. (2017). Retrieved from http://ec.europa.eu/eurostat/documents/276524/7736915/EU-SDG-indicator-set-with-covernote-170531.pdf

European Commission. (2017a). New horizons - Future scenarios for research \& innovation policies in Europe (project Bohemia). 
European Commission. (2017b). Report of the independent High Level Group on maximising the impact of EU Research \& Innovation Programmes, $L A B-F A B-A P P$ - Investing in the European future we want.

European Commission. (2018). Mission-oriented research and innovation policy, RISE.

Fresco, L., Martinuzzi, A., Anvret, M., Bustelo, M., Butkus, E., Cosnard, M., ... others. (2015). Commitment and Coherence. Ex-Post-Evaluation of the 7th EU Framework Programme (20072013) (Report of High Level Expert Group). Brussels: European Commission.

Gregersen, C., Mackie, J., \& Torres, C. (2016). 'Implementation of the 2030 Agenda in the European Union: Constructing an EU approach to Policy Coherence for Sustainable Development'. Document de Travail, (197).

Hametner, M., Dimitrova, A., Endl, A., \& Martinuzzi, R.-A. (2015). Monitoring the FP7 contribution to the EU's SD objectives - Policy Briefing (policy briefing No. 11).

Martinuzzi, R.-A., Hametner, M., Katzmair, H., Stahl, B., Dimitrova, A., Lorenz, W., ... Wakunuma, K. (2016). Network Analysis of Civil Society Organisations' participation in EU Framework Programmes. Vienna \& Leicester: WU \& De Montfort University. Retrieved from http://ec.europa.eu/research/swafs/pdf/pub_public_engagement/ki-04-17-578-en.pdf

Reillon, V. (2018). Preparing FP9. Designing the successor to the Horizon 2020 research and innovation framework programme (IN-DEPTH ANALYSIS No. PE 620.215). EPRS | European Parliamentary Research Service Members' Research Service. 


\section{Annex 1: List of position statements issued before the publication of Horizon Europe analysed in this report}

\begin{tabular}{|c|c|}
\hline Document System & $\begin{array}{l}\text { Number of coded } \\
\text { segments }\end{array}$ \\
\hline Documents & 4847 \\
\hline 1 ALLEA et al FP9 Living_Together_Missions_for_Shaping_the_Future & 89 \\
\hline 2 ALLEA-Statement-FP9_1 & 100 \\
\hline 3 APRE-PP-FP9_1 & 52 \\
\hline 4 BusinessEurope & 5 \\
\hline 5 CAN Europe position on EU Framework for Research \& Innovation & 47 \\
\hline 6 CESEAR_201706_27_final_FP9_Paper & 152 \\
\hline $7 \quad$ CIS_widening-position-paper-Belgium_1 & 27 \\
\hline $8 \quad$ CLORA & 14 \\
\hline $9 \quad$ Coimbra Group position paper on FP9 - $100 c t 2017$ & 70 \\
\hline $\begin{array}{ll}1 & \text { COST_FP9_position_paper } \\
0 & \end{array}$ & 36 \\
\hline 11 Cypriot-Universities-position-paper-FP9_1 & 67 \\
\hline 12 Digital_Europe & 52 \\
\hline $\begin{array}{l}13 \text { DSW_Deutschestiftungweltbevölkerung_10-recommendations-for- } \\
\text { H202 }\end{array}$ & 37 \\
\hline 14 EARTO_First_Thinking_Forward_for_FP9 & 20 \\
\hline 15 EASSH_Bratislava_final_def & 25 \\
\hline
\end{tabular}


17 EMBL_s_vision_for_the_9th_Framework_Programme_for_Research_a 62 nd_

1 ERAC_Opinion_on_Interim_Evaluation_of_H2020_Outlook_at_FP9 126

8

1 ERC-ScC-Statement-FP9_1

8

9

2 ERRIN-FP9-Position_1

0

21 EUA_Vision_for_FP9

2 EUA-next-framework-programme-for-research-and-innovation-_fp9_ 98

2

23 EULIFE_JAN2017

2 eurodoc_fp9statement

4

25 EuroTech-Universities-Alliance-Position-on-FP9

2 fp9_position_paper_tekes_12_2017

6

27 FP9-CNR-Italy-position-paper-Final_7

2 fp9positionpaper_eurospace_20nov2017

8

2 GIURI-Italy-FP9-position-paper-final_1

9

30 Guild-position-on-fp9_12-june-2017 (a) and guild-statement-onssh_final (b) 
31 Helmholtz_201803-Seizing-the-opportunities-of-European-research

32 helsinki_group-position-paper-h2020-interim-evaluation-adopted_ 74

33 hera_fp9_first_response_0

35 Joint_Declaration_Industry__RTOs_on_FP9_-_7_June_2017_-_Final 11

$36 \operatorname{jrc109610} 44$

37 JTI-Industry-Associations-position-paper-FCH-factsheet

39 NETH-ER-visionPaperFP9_nov17_web

0

41 Orgalime_pp_Horizon2020_final

$4 \quad$ Perspectives-for-the-ECSEL-Joint-Undertaking-beyond-the-2020-Ho 37

2

43 Poland_Position-paper-FP9-PolSCA_1

\begin{tabular}{llr}
\hline 4 & Science_Europe & 17 \\
6 & & \\
\hline 47 & SFIC_Opinion_on_H2020_Midterm_Review_FP9 & 2 \\
\hline 4 & Technopolis_Group_H2020_position_paper_2017_def & 8 \\
8 &
\end{tabular}


0

51 V4-Position-statement-final-version_1

53 YAE-FP9-Statement-Jan2018_1

54 YERUN_FP9-Position-Paper_Final

0 Switzerland_Annex_1_Recommendations_for_Further_Simplicatio $\mathrm{n}$

6 CY FINAL-Position-Paper-of-Cyprus-on-FP9_1

6 CZ Tschechien_Horizon_2020_Interim_Evaluation_Czech_Republic 50 2

63 DE_Federal_government_FP9_guidelines_September_2017 162 
paper_on_a_modernised_and_financially_sustainable_MFF_-_

78 NO Norwegian_Position_Paper_on_FP9_First-07_03_17-final 
$8 \quad$ scotland

1

8 SE Schweden

2

83 SI_Expert_Group_Report_FP9

8 SK Slovakia_FP9_FINAL

39

4

85 UK Wales Welsh-Government-FP9-Position-Paper_3

8 UK-FP9-position-paper_1

54

6 


\begin{tabular}{|l|l|}
\hline Name & Organisation \\
\hline $\begin{array}{l}\text { Univ.Prof. Dipl.-Ing. Dr. } \\
\text { Dr.h.c.mult. Martin Gerzabek }\end{array}$ & $\begin{array}{l}\text { Institute of Soil Research, University of Natural Resources } \\
\text { and Life Sciences, Vienna, BOKU }\end{array}$ \\
\hline $\begin{array}{l}\text { Univ.Prof. Dr. Nebojsa } \\
\text { Nakicenovic }\end{array}$ & $\begin{array}{l}\text { Deputy Director General/Deputy Chief Executive Officer of } \\
\text { the International Institute for Applied Systems Analysis } \\
\text { (IIASA) }\end{array}$ \\
\hline a. Prof. Dr. André Martinuzzi & $\begin{array}{l}\text { Head of Institute for Managing Sustainability, Vienna } \\
\text { University of Economics and Business }\end{array}$ \\
\hline Prof. Dr. Ute Stoltenberg & $\begin{array}{l}\text { Senior Professorship for Sustainibility Science, } \\
\text { Leuphana University Lüneburg }\end{array}$ \\
\hline $\begin{array}{l}\text { O.Univ.Prof. Dipl.-Ing. } \\
\text { Dr.techn. A Min Tjoa }\end{array}$ & $\begin{array}{l}\text { Full Professor at the Institute of Information Systems } \\
\text { Engineering at the Vienna University of Technology }\end{array}$ \\
\hline Prof. Dr. Dirk Messner & $\begin{array}{l}\text { Director of the the German Development Institute / } \\
\text { Deutsches Institut für Entwicklungspolitik (DIE) }\end{array}$ \\
\hline Dr. Evelina Santa-Kahle & $\begin{array}{l}\text { SDG Expert, for this report in a personal capacity. } \\
\text { Unit 700 Policy Issues, Digitalization, and Transfer, Dep. } \\
\text { Sustainability: Provision for the Future, Federal Ministry of } \\
\text { Education and Research, Germany. }\end{array}$ \\
\hline $\begin{array}{l}\text { Univ.-Prof. Dipl.-Ing. } \\
\text { Dr.mont. Peter Moser }\end{array}$ & $\begin{array}{l}\text { Head of the Chair of Mining Engineering and Mineral } \\
\text { Economics } \\
\text { Vice Rector for Infrastructure and International Relations, } \\
\text { Montanuniversität Leoben }\end{array}$ \\
\hline $\begin{array}{l}\text { Ao. Univ.-Prof. Dr. Helmut } \\
\text { Haberl }\end{array}$ & $\begin{array}{l}\text { Deputy Director of the Institute of Social Ecology, University } \\
\text { of Natural Resources and Life Sciences Vienna }\end{array}$ \\
\hline
\end{tabular}

Univ.Prof. Dipl.-Ing. Dr. Dr.h.c.mult. Martin Gerzabek is an Austrian ecologist and soil scientist. He is Professor of Ecotoxicology and Isotope Application and was Rector at the University of Natural Resources and Life Sciences Vienna from 2010 to 2018 . He is a member of the Board of the Euroleague for Life Sciences (ELLS), which he chaired from 2009 to 2010. In 2009, Gerzabek was appointed corresponding member to the mathematics and natural sciences division in the Austrian Academy of Sciences. In addition, he has been vice president of the AAER (Austrian Association for Agricultural Research) since 2009. Gerzabek has received several awards for his scientific work, for example, the "Pro Merito" badge of honour in gold for outstanding achievements regarding radiation protection in 2004. In 2006, he received the honorary membership of the Austrian Soil Science Association for outstanding achievements in soil science in Austria and in 2011, the Emil Ramann Medal of the German Soil Science Society. 
Ao.Univ.Prof. Dr. Helmut Haberl is associate professor of Human Ecology at the Institute of Social Ecology, University of Natural Resources and Life Sciences Vienna. He was head of the Institute of Social Ecology since 2012-2017. He was researcher at the Austrian Institute of Applied Ecology 1989-2002 and served as head of its Dept. of Energy and Environment, 19931997. In 2017 Haberl received an Advanced ERC Grant, valued at almost 2.5 million EURO over a period of five years. Together with his collaborators in the Institute of Social Ecology and at Humboldt University, Helmut Haberl investigates the role of material stocks for the development towards a sustainable society.

a. Prof. Dr. André Martinuzzi has more than 20 years of experience in coordinating and leading EU-wide research projects for the European Commission, as well as for international organizations and ministries. He is an expert in the fields of evaluation research, CSR, sustainable development, and knowledge brokerage. As a member of the European Evaluation society, he leads the working group "Evaluating Sustainable Development" and coordinated many conferences in the frame of the "EASY-ECO - Evaluation of Sustainability" Programs. André is also a member of the CEMS faculty group "Business and the Environment" and of the German Academic Association for Business Research (VHB).

Prof. Dr. Dirk Messner is a German political scientist and director of the German Development Institute, Professor of Political Science at the University of Duisburg. He has been Director of the "German Development Institute / Deutsches Institut für Entwicklungspolitik (DIE)" since 2003. He is also Co-Director of the "Käte Hamburger Kolleg / Centre for Global Cooperation Research", University Duisburg-Essen, which was established in 2012. Based on his research, Dirk Messner is engaged in highranking policy advisory councils. For example, he is Co-Chair (since 2013) of the "German Advisory Council on Global Change" ("Wissenschaftlicher Beirat der Bundesregierung Globale Umweltveränderungen" (WBGU)) and member of the "China Council on Global Cooperation on Development and Environment" (CCICED). His work areas focus on Global Change and Sustainable Development, Transformation towards the Decarbonisation of the global Economy, Globalization and Global Governance and International Cooperation and human behaviour.

Univ.-Prof. Dipl.-Ing. Dr.mont. Peter Moser (Head of the Chair of Mining Engineering and Mineral Economics, Vice Rector für Infrastructure and International Relations, Montanuniversität Leoben): Since 2008 appointment as full professor and chair for mining engineering, mining technology and mountain management, since 2011 Vice-Rector for Infrastructure and International Relations at Montanuniversität Leoben, he is also cocoordinator of the international forum in the Austrian Rectors Conference. The forum develops strategic concepts for the internationalisation of Austrian Universities Conference and ensures the exchange of information between the universities. 
Univ.-Prof. Dr. Nebojsa Nakicenovic is Deputy Director General/Deputy Chief Executive Officer of the International Institute for Applied Systems Analysis (IIASA), and former Professor of Energy Economics at the Vienna University of Technology. Among other positions, Prof. Dr. Nakicenovic is Member of the United Nations Secretary General Special Advisory 10-Member Group to support the Technology Facilitation Mechanism; United Nations Secretary General High-Level Technical Group; Member of theAdvisory Council of the German Government on Global Change (WBGU); Member of the International Council for Science (ICSU) Committee on Scientific Planning and Review, and Co-Chair of the Global Carbon Project; Member of the Board, Climate Change Centre Austria(CCCA); Member of the Working Group of the Austrian Panel on Climate Change (AG-APCC); Member of the Panel on Socioeconomic Scenarios for Climate Change Impact and Response Assessments; Member of the Renewable Energy Policy Network for the 21st Century (REN21) Steering Committee; Member of the International Advisory Board of the Helmholtz Programme on Technology, and Member of the Earth League.

Evelina Santa-Kahle, is senior policy officer in the German Federal Ministry for Education and Research, and works at Unit 700 Policy Issues, Digitalization, and Transfer, Dep. Sustainability: Provision for the Future, Federal Ministry of Education and Research, Germany. For this report she speaks in a personal capacity.

Prof. Dr. Ute Stoltenberg is university professor at Leuphana University Lüneburg and owner of the Senior Professorship for Sustainability Science. She was Member of the Academic Senate of the University of Lüneburg (1997 - 2007) as well as various Senate Commissions (until 2013). She was Visiting professor at the University of Klagenfurt 2013/2014 and has worked in Italy, Switzerland, Austria, El Salvador, Chile, Poland, Great Britain, China. Stoltenberg founded the German-language network "Teacher Education for Sustainable Development LeNa" in 2013 and was its coordinator until 2017. From 2008 to 2017 she was a member of the German National Committee for the UNESCO programme "Man and the Biosphere" (MAB); since 2018 she has been a member of the Board of Trustees of the Hamburg Climate Protection Foundation.

O.Univ.Prof. Dipl.-Ing. Dr.techn. A Min Tjoa has been a full professor at the Vienna University of Technology since 1994. He is the executive chairperson of the Austrian National Competence Center for Security Research (Competence Centers for Excellent Technologies Initiative of the Austrian government). He was visiting professor at the Universities of Zurich, Kyushu and Wroclaw (Poland) and at the Technical Universities of Prague and Lausanne (Switzerland). He was the president of the Austrian Computer Society from 1999 to 2003. He is also the Austrian National Coordinator of ASEA-UNINET (ASEAN-European University Network). He is currently the Chairperson of the United Nations Commission on Science and 
Technology for Development. In 2011 he received the honorary doctoral degree (Dr.h.c.) from the Czech Technical University in Prague and the honorary professor degree of the University of Hue (Vietnam). His current research focus areas are data warehousing, cloud computing, semantic web, security, and non-standard IT-applications. He has published more than 200 peer reviewed articles in journals and conferences. 


\section{Annex 3 Expert interview guideline and questions}

\section{Interviews Part 1}

(before the proposal for Horizon Europe was published - February-April 2018)

Interviews took about 30 minutes

1. Brief description of your own position and experience with SGDs at European Research Policy level

2. The EU Research Framework Programs and the Implementation of the SDGs (Agenda 2030): Can you see the effectiveness of the SDGs in FP7 and H2020, which problems arise from this consideration?

3. Who and what are the SDG relevant drivers in the European discourse on research and innovation (with which topics)?

4. How can the SDGs be better anchored in RTI policy, how can they be made effective in research policy? Where and how could the SDGs act as an orientation or implementation framework for European Research Programs? Which instruments are suitable, which instruments would have to be created first?

5. What exactly should one look for when analysing the first draft of the new Framework Program FP9 - how to anchor the integration and implementation of the SDGs there more effectively?

6. Are there any international best practices or flagship programs/initiatives in research and innovation policy that already integrate the SDGs in an exemplary way or that promote them?

\section{Interviews Part 2}

(after the proposal for Horizon Europe was published - June 2018)

Responses were shared in written and oral format (telephone interviews)

1) How do you rate the integration of the SDGs in the Horizon Europe proposal?

2) Where do you miss the relation to the SDGs and why? Which potentials are not exploited in the proposal?

3) Do you already see concrete proposals that could effectively drive the implementation of the SDGs?

4) Can the SDGs in this proposal unfold their potential as a "social contract" for a better coexistence? 
5) Is the proposal suitable for further advancing the SDGs at the country level?

Do you see the following topics (sufficiently) dealt with in the proposal?

- SDGs in respect to policy coherence

- SDGS in respect to monitoring and "sustainability proofing"

- SDGs related to citizen participation and knowledge transfer

- SDGs in connection with the expansion of the European Research Area and widening activities, as well as in connection with international cooperation

- The role of the humanities and social sciences in the context of the SDGs or related topics

- Is sufficient attention given to interdisciplinarity, which is not only required for the SDGs?

\section{Annex 4 List of figures}

Figure 1: In the figure above each circle represents a category of megatrends containing a set of SDGs. The titles of the scenarios are represented by the curved writing. (Bohemia Foresight Study 2017, p14)

Figure 2 shows the interrelation of the EU and MS level policies activated for a missionoriented approach.(ESIR Memorandum, p.14)

Figure 3 The SDGs as grand vision for the definition (and selection) of challenges and missions (Mazzucato 2018, p11)

Figure 4 Tagcloud of the most frequent words in the document corpus

Figure 5 German Committee Future Earth (2016, p12-13)

http://futureearth.org/sites/default/files/2016_report_contribution_science_sdgs.pdf

Figure 6 World in 2050 Initiative: "Transformations to Achieve the Sustainable

Development Goals" (2018, p6) http://pure.iiasa.ac.at/id/eprint/15347/

Figure 7 Sustainable Development Report Dashboards: Transformations to Achieve the Sustainable Development Goals https://dashboards.sdgindex.org/\#/ Screenshot retrieved July $29^{\text {th }} 2018$.

Figure 8 Societal impact pathway indicators.Screenshot from the document accompanying the Horizon Europe proposal IMPACT ASSESSMENT, p47. 


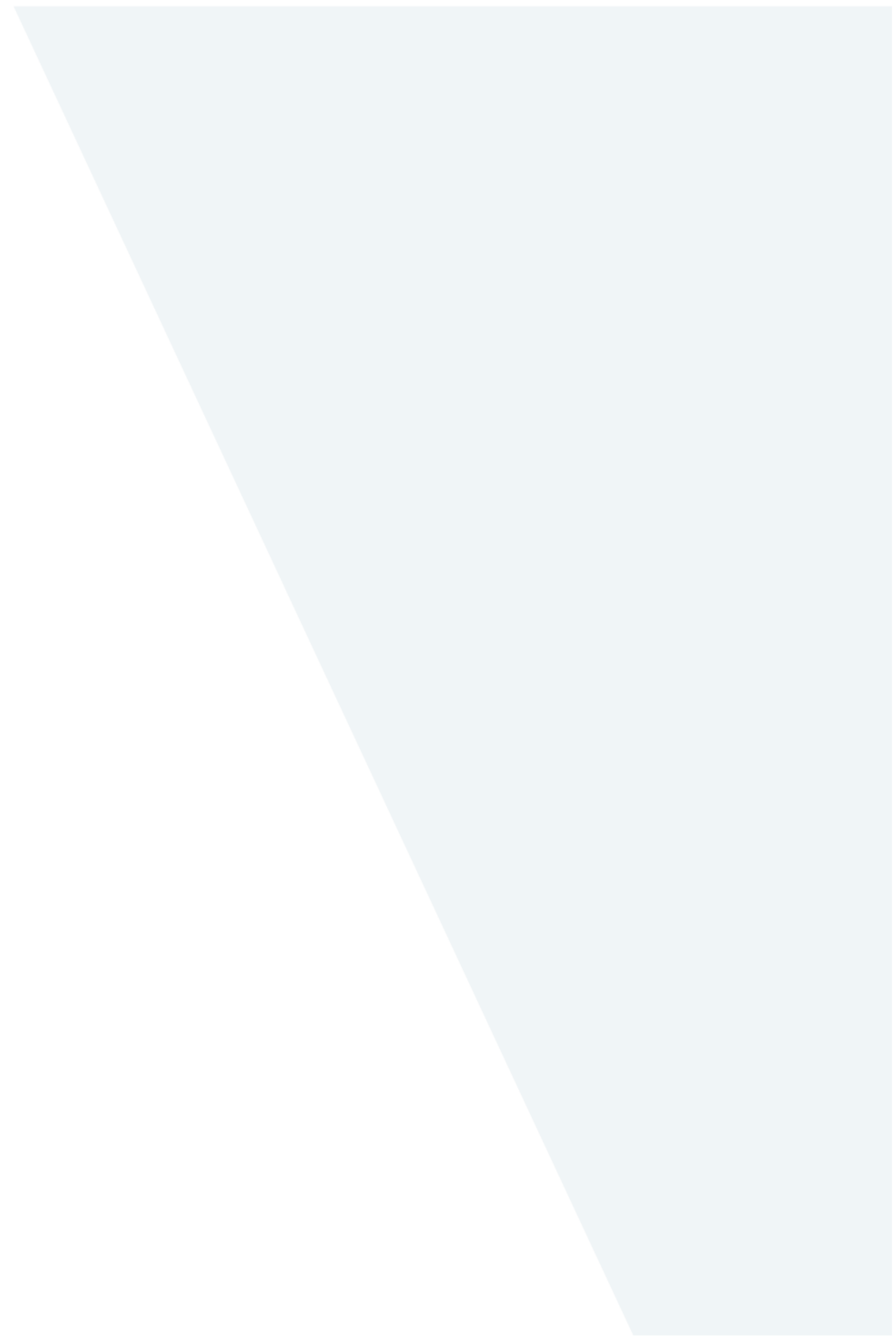

